\title{
Epithelial Mesenchymal Transition and Tissue Healing
}

\author{
Review \\ Hala Elwy Hashem \\ Article \\ Histology and Cell Biology Department, Faculty of Medicine, Zagazig University, Egypt
}

\begin{abstract}
Epithelial mesenchymal transition (EMT) is the ability of the cells to lose the epithelial features with gaining of mesenchymal one. It is a dynamic and reversible process induced by damage, hypoxia or inflammation. The execution of EMT events could be complete or partial during tissue repair of different organs. During wound healing, EMT has important role for re-epithelialization, angiogenesis and for Langerhans cells immunologic role. On the other hand, sustained EMT is a key mechanism underlying the wound scaring, fibrotic pathology of multiple organs, cataract and endometriosis. Hence, the understanding of EMT regulation during wound healing and tissue repair has important clinical implications as chronic wounds represent major health care costs. EMT could yield adult cells with stem cell characteristics. Therefore, one could predict that, it contributes to the pool of different progenitor cells to maintain organs homeostasis. Further analyses are necessary to determine whether EMT in normal tissues leads to the production of normal stem cells.
\end{abstract}

Received: 19 Jan 2019, Accepted: 04 Feb 2019

Key Words: Epithelial, healing, mesenchymal, tissue, transition

Corresponding Author: Hala Elwy Hashem, MD, Histology and Cell Biology Department, Faculty of Medicine, Zagazig University, Egypt, Tel.: +2 01023728595, E-mail: elwyhala@yahoo.com

ISSN: 2536-9172, Dec 2018 Vol.2, No.2

Epithelial mesenchymal transition (EMT) is cellular plasticity with ability of cells to alter their phenotypic and morphological characteristics leading to transdifferentiation of epithelial cells into motile mesenchymal cells ${ }^{[1]}$.

The idea that epithelial cells can down regulate epithelial characteristics and acquire mesenchymal characteristics arose in the early 1980s from observations made by Elizabeth Hay 1980 who described epithelial to mesenchymal phenotype changes in the primitive streak of chick embryos ${ }^{[2]}$.

Originally it was thought of EMT as a transformation, suggesting a unidirectional and committed switch. However, EMT is now considered a transition suggesting a transient and reversible process ${ }^{[3]}$. Subsequently, the term "transformation" was replaced with "transition" reflecting in part the reversibility of the process and the fact that it is distinct from neoplastic transformation. The reverse process of EMT is termed mesenchymal-to-epithelial transition $(\mathrm{MET})^{[4]}$.

\section{The difference between epithelial cells and mesenchymal cells (Fig.1a\&b):}

\section{Characteristics of Epithelial Cells:}

- Typically a sheet 1 cell thick.
- Individual cells abutting each other.

- Regularly spaced cell junctions and adhesions between neighboring cells.

- Tight adhesion between cells resulting in inhibition of movement away from the monolayer.

- Enclose a 3-dimensional space within.

- Gives structural definition and rigidity.

- Epithelial sheet is polarized.

- Apical and basal surfaces often very different.

- Adheres to different substrates.

- Has different function.

- Movement of epithelial cells is done en block with the motive force usually generated within the sheet by the sum of the cells' shape changes. e.g: during intestinal cell renewal ${ }^{[5]}$.

\section{Characteristics of Mesenchymal Cells:}

- Lack regimented structure. 
- Weak adhesions which allow for ease of mobility.

- Forms irregular structures that are not uniform in composition or density.

- More extended and elongated in shape.

- Lacks rigid topological specialization (no compartments).

- Cells move as individuals, not en block, often leaving a trailing region behind.

- Migration mechanistically different and more dynamic.

- Filopodia and front end back end polarity (frontrear), migration capacity, cell-cell adhesion, and extracellular matrix interactions: At the front of the cell is the leading edge, Here, actin polymerization in the direction of migration allows cells to extend the leading edge of the cell and to attach to the surface. At the rear of the cell, adhesions are disassembled and bundles of actin microfilaments, called stress fibers, contract and pull the trailing edge forward to keep up with the rest of the cell. Without this frontrear polarity, cells would be unable to coordinate directed migration ${ }^{[6]}$.

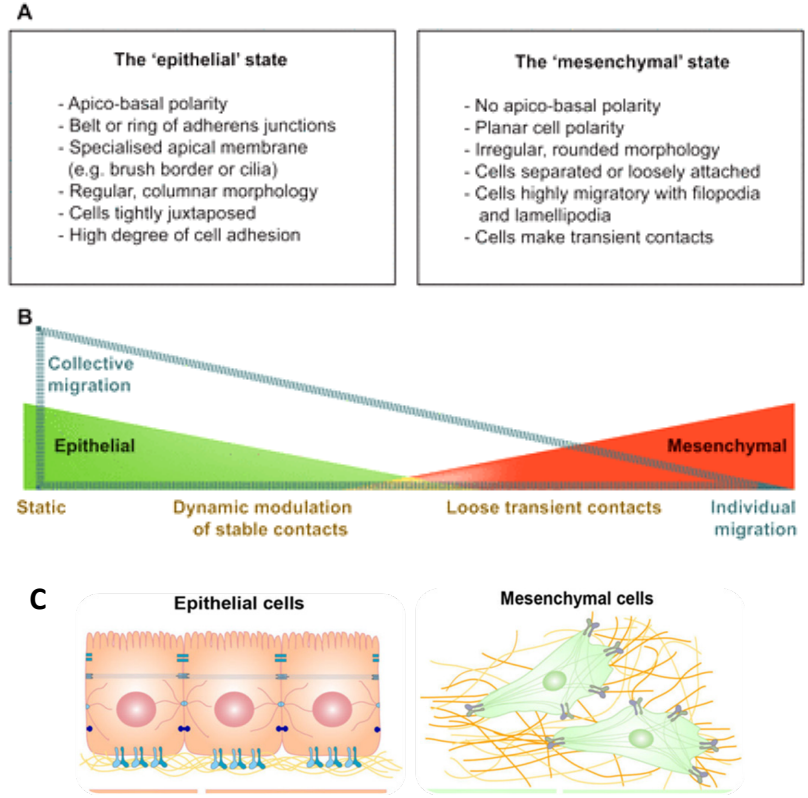

Fig. 1a\&b: The difference between epithelial cells and mesenchymal cells (a,b: 7; C: 8).

\section{II- The events of Change in cell shape (Fig.2):}

Change in cell shape, generally by an apical actinmyosin contractile mechanism and/or changes in adhesion.
Through a bottle-shaped stage, which may have two functions: by constricting their apices cells may displace much of their intracellular contents basally and initiate movement out of the epithelium? Perhaps more important, apical constrictions reduce the amount of non-adhesive apical membrane and circumferential, apical junctions that must finally be broken upon ingression. It also reduces the size of the hole left in the epithelium. It is generally thought that apical constriction is driven by an actin-myosin-based contraction, while the apical membrane is reduced by endocytosis. Changes in adhesion may also contribute to cell shape change on $\mathrm{EMT}^{[9]}$.

These cell shape changes are preceded and/or accompanied by alterations in gene expression including up-regulation of hyperproliferation associated keratin 6 (K6) and K16, retraction of keratin filaments (which normally associates with desmosomes and hemidesmosomes) from the cell periphery, as well as major reorganization of the actin cytoskeletal network (which normally associates with adherens junctions $)^{[10]}$. Mechanistically, the impact of endocytosis on these processes, which we did not cover in this review, can be rationalized within the same basic principle that posits that the endocytic machinery defines a vast program of intracellular communication that integrates different, apparently distinct, territories of cell regulation, as according to the concept of "endocytic matrix"[11].

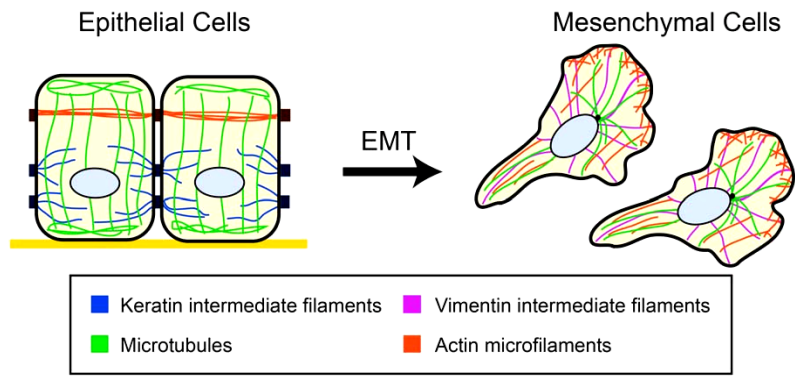

Fig. 2: Cytoskeletal changes during EMT ${ }^{[12]}$.

\section{De-epithelializtion:}

It is the loss of the coherent contact between neighbors that characterizes a particular epithelium, and the eventual loss of an apical membrane domain. This involves a loss of the extensive circumferential apical junctions, specifically the circumapical tight and adherens junctions, in the case of epithelia that are physiologically and mechanically very impermeant and coherent. Cell-cell junctions associated with cytoskeletal filaments are the basis of the tensile strength and structural integrity of epithelial tissues. A typical epithelial cell contains several major classes of functionally diverse cell-cell junctions: adherens junctions, tight junctions, desmosomes, and gap junctions. Of these, only adherens junctions (AJ) and tight junctions (TJ) are known to play a necessary regulatory role in maintaining the epithelial program ${ }^{[13]}$. How these processes occur 
is not understood. The evidence suggests that targeted endocytosis of epithelial junctions and adhesion molecules may be important and the apical membrane may eventually be completely eliminated by endocytosis.

Cell-cell adhesion is altered, characterized by reduced desmosomal adhesion between cells as well as the reduced presence of adherens junction components such as E-cadherin, leading to appearance of intercellular gaps ${ }^{[14]}$. Failure to down-regulate desmosomal adhesion, as in mice where protein kinase $\mathrm{C}$ is deficient, is associated with delayed wound healing ${ }^{[15]}$. Down-regulation of adherens junctions and tight junctions, but not desmosomes, has been shown to be mediated by ephrin-B-EphB signaling, as epidermal-specific knockout of both ephrin-B1 and ephrin-B2 results in impaired wound closure, characterized by persistent adherens junctions between cells in the migrating front ${ }^{[14]}$.

\section{Basal lamina disruption:}

The profound phenotypic transition in EMT involves the epithelial cells disrupting the basement membrane. Matrix metalloproteinases (MMPs) are known to cleave components of basement membranes, but MMP-basement membrane crosstalk during EMT in vivo is poorly understood. However, MMPs have been reported to play a role in EMT-related processes and a variety of basement membrane fragments have been shown to be released by specific MMPs in vitro and in vivo exhibiting distinct biological activities ${ }^{[16]}$.

\section{Ingression:}

It is the withdrawal of the ingressing cell's apex from the epithelial layer and into the deep layer. It differs from de-epithelialization in that a cell could de-epithelialize and not move out of the sheet. Normal ingression is associated with de-epithelialization and adoption of basal mesenchymal characteristics, including an active motility and strong traction on deep tissues or structures, to pull the cell out of the epithelium ${ }^{[17]}$. Front rear movement: (At the front of the cell is the leading edge, which is often defined by a flat ruffling of the cell membrane called the lamellipodium or thin protrusions called filopodia. Here, actin polymerization in the direction of migration allows cells to extend the leading edge of the cell and to attach to the surface. At the rear of the cell, adhesions are disassembled and bundles of actin microfilaments, called stress fibers, contract and pull the trailing edge forward to keep up with the rest of the cell. Without this front-rear polarity, cells would be unable to coordinate directed migration $)^{[18]}$. A driving force behind this motility is the loss of the polarized cytoskeleton in epithelial cells, and the development of lamellipodia in the advancing edge of the transitioning mesenchymal cells ${ }^{[19]}$.
4. Progression towards a mesenchymal phenotype (Fig.3):

Specification toward a mesenchymal phenotype initiates many important changes in gene expression and protein function that must all work in concert for a developmental EMT to occur correctly ${ }^{[20]}$.

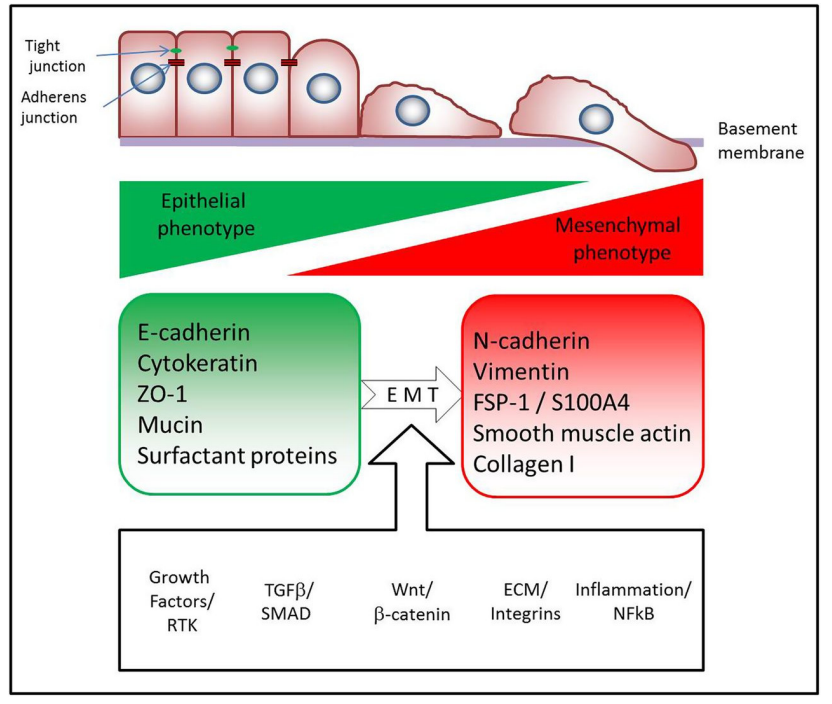

Fig. 3: progression towards mesenchymal phenotype during EMT $^{[20]}$.

1. loss of epithelial cell markers:

loss of epithelial cell markers: It is the first step of EMT during which there is decreased expression of E-cadherin $^{[21]}$ which is responsible for maintaining the epithelial cells' lateral contacts via adherens junctions, as well as cell adhesion and relative immobility in the tissue $^{[22]}$. E-cadherin downregulation is also mediated through upregulation of vimentin, an intermediate filament that decreases E-cadherin trafficking to the cell surface ${ }^{[23]}$.

2. The cell then progresses towards a mesenchymal phenotype:

by gaining mesenchymal markers and capabilities. This change is orchestrated by temporally regulated expression of the following proteins. Vimentin ( intermediate filament, in favor of the cytokeratin, that decreases E-cadherin trafficking to the cell surface. Neural cadherin (N-cadherin): adhesion molecules. Matrix metalloproteinases (MMPs): responsible for the metabolism of extracellular matrix (ECM) component of connective tissue. During this process, the continued enhanced expression of MMPs, released by a variety of cells (macrophages, keratinocytes, endothelial cells, and fibroblasts) plays crucial roles in degrading substrates of the provisional wound matrix ${ }^{[22]}$. Integrin: Matrix receptors interact with extracellular matrix (ECM) 
components are then upregulated to increase motility and Fibronectin: extracellular matrix (ECM) components ${ }^{[24]}$.

Cell-matrix adhesion alterations occur to facilitate migration. Specific changes include redistribution of $a 2 b 1$, $\mathrm{a} 3 \mathrm{~b} 1$, and a6b4 integrins (receptors for collagen or laminin) on keratinocyte surface, activated expression of a 5b1, avb6, a9b1, and avb5 integrin (receptors for fibronectin, tenascin, or vitronectin), as well as increased metalloproteinase activity that facilitates keratinocyte migration by promoting ECM remodeling and hemidesmosome breakdown ${ }^{[25]}$. Elevated expression of vimentin and fibroblast-specific protein 1 (FSP1) has been noted in the migrating epithelial tongues of acute wounds of thermal burn patients and in hypertrophic scars ${ }^{[26]}$. In a recent study, the spatiotemporal profile of keratinocyte migration and proliferation during wound healing in mouse tail was carefully dissected, again showing that these cellular events can be uncoupled ${ }^{[27]}$.

Gene expression analysis of the migrating leading edge revealed an enrichment of genes involved in cell migration (e.g., metalloproteinases) and cell adhesion (e.g., protocadherins, a5-integrin, desmosome, and gap junction proteins). Genes controlling cytoskeleton and actin remodeling (e.g., actin regulators, myosin, and tubulin) are also part of the leading edge molecular signature, consistent with epidermal migration being driven by actinmyosin filaments that generate traction forces and actin polymerization that generates protrusions ${ }^{[28]}$.

\section{Partial EMT:}

It is noteworthy that EMT process may not always be a complete. In some instances, cells may exist along a gradient where incomplete transition occurs, and both epithelial and mesenchymal characteristics are exhibited by the same cell ${ }^{[29]}$. There are several reports describing a partial or incomplete EMT phenotype of advanced carcinomas, displaying some mesenchymal features, but with a retention of well-differentiated epithelial-cell characteristics ${ }^{[30]}$. When the epithelial cell markers continue to be expressed, but the mesenchymal cells markers have been already obtained, such cells possibly represent the intermediate stage of EMT, or namely a partial EMT ${ }^{[31]}$.

The simple fact that these cells are at the edge of the sheet endows them with a distinct polarity: on one side they contact other cells, and on the other they find a free edge. This difference is reflected in their apico-basal polarity; whereas the leading edge cells maintain apicobasal polarity and junctions at the site of cell-cell contact, these are lost from the free edge resulting in a cell that is only partially apico-basal polarised. This can be seen by an absence of staining for certain polarity proteins, such as Discs large and Crumbs, or E-cadherin. Thus, using current terminology, cells at the leading edge would be desc ribed as 'partially'undergoing a 'partial EMT, however, within our framework, epithelial leading cells can be considered to be acquiring certain mesenchymal features ${ }^{[7]}$.

Partial EMT is also possible, and this occurs when $\geq 1$ of the key characteristics of complete EMT are not exhibited, such as loss of cell-cell contact. For example, during re-epithelialization of cutaneous wounds, keratinocytes undergo a series of changes reminiscent of EMT, including loss of polarity, rearrangement of the actin cytoskeleton, alterations in cell-cell contacts, and breakdown of basement membrane; however, these cells retain some intercellular junctions and migrate as a cohesive cell sheet.24 However, angiogenic EC do not usually separate from their neighbors, suggesting that angiogenesis may involve a partial EndoMT ${ }^{[32]}$ (Fig. 4\&5). Also, partial EMT was reported to taking place during wound healing and mammary tubulogenesis ${ }^{[33]}$.

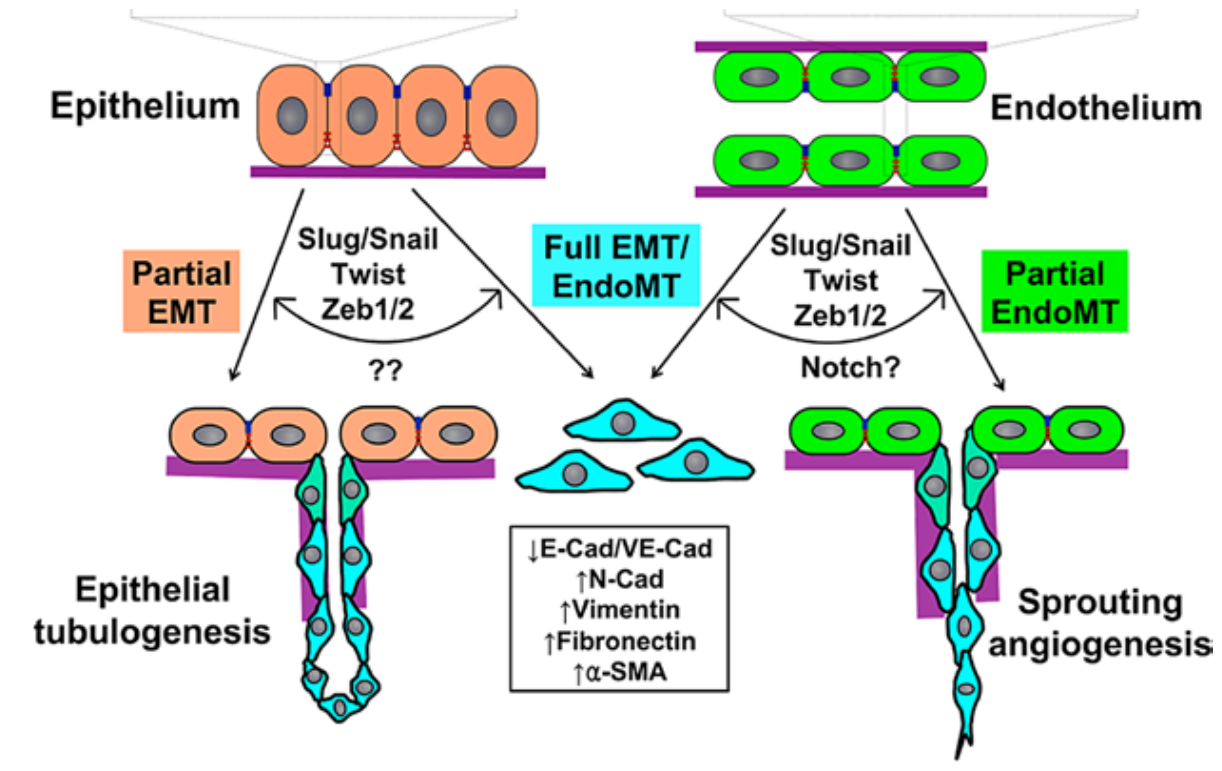

Fig. 4 : Partial EMT ${ }^{[32]}$. 


\begin{tabular}{|c|c|c|c|}
\hline & EMT & Wound re-epithelialization & References \\
\hline Cell-cell adhesion & $\begin{array}{l}\text { Destabilization of adherens junctions; } \\
\text { down-regulating E-cadherin; } \\
\text { up-regulating N-cadherin and NCAM; } \\
\text { dissolution of apical tight junctions } \\
\text { and desmosomes }\end{array}$ & $\begin{array}{l}\text { Reduced desmosomal adhesion; } \\
\text { reduced E-cadherin }\end{array}$ & $\begin{array}{l}\text { Beaudry et al., } 2010 \\
\text { Coulombe, } 1997 \\
\text { Garrod et al., } 2005 \\
\text { Kuwahara et al., } 2001\end{array}$ \\
\hline $\begin{array}{l}\text { Cell-matrix } \\
\text { adhesion }\end{array}$ & $\begin{array}{l}\text { Down-regulation of } \alpha 6 \beta 4 \text {; requirement } \\
\text { for } \alpha 3 \beta 1 \text {; increased } \alpha 5 \beta 1, \alpha v \beta 6, \alpha 1 \beta 1 \\
\text { and } \alpha 2 \beta 1 \text {; increased MMPs }\end{array}$ & $\begin{array}{l}\text { Redistribution of } \alpha 2 \beta 1, \alpha 3 \beta 1 \text {, and } \\
\alpha 6 \beta 4 \text {; activated expression of } \\
\alpha 5 \beta 1, \alpha v \beta 6, \alpha 9 \beta 1 \text {, and } \alpha v \beta 5 \text {; } \\
\text { increased MMPs }\end{array}$ & $\begin{array}{l}\text { Arnoux et al., } 2005 \\
\text { Lamouille et al., } 2014\end{array}$ \\
\hline $\begin{array}{l}\text { Intermediate } \\
\text { filaments }\end{array}$ & $\begin{array}{l}\text { Decreased cytokeratin; } \\
\text { increased vimentin }\end{array}$ & $\begin{array}{l}\text { Altered cytokeratin; } \\
\text { increased vimentin? }\end{array}$ & $\begin{array}{l}\text { Arnoux et al., } 2005 \\
\text { Lamouille et al., } 2014\end{array}$ \\
\hline Mode of migration & $\begin{array}{l}\text { Single cell migration or collective } \\
\text { migration }\end{array}$ & Collective migration & $\begin{array}{l}\text { Arnoux et al., } 2005 \\
\text { Lim and Thiery, } 2012 \\
\text { Nieto et al., } 2016 \\
\text { Park et al., } 2017\end{array}$ \\
\hline $\begin{array}{l}\text { Growth factors and } \\
\text { signaling cascades }\end{array}$ & $\begin{array}{l}\text { TGF- } \beta, \text { EGF, FGF, HGF, } \\
\text { Wnt, Hh, Notch }\end{array}$ & $\begin{array}{l}\text { TGF- } \beta \text {, EGF, FGF, HGF, KGF, } \\
\text { Wnt, Hh, Notch }\end{array}$ & $\begin{array}{l}\text { Arnoux et al., } 2005 \\
\text { Bielefeld et al., } 2013 \\
\text { Eming et al., 2014 } \\
\text { Lamouille et al., } 2014\end{array}$ \\
\hline $\begin{array}{l}\text { EMT-transcription } \\
\text { factors }\end{array}$ & $\begin{array}{l}\text { (+) Snail, Slug, Zeb1, Zeb2, Twist } \\
\text { (-) Grhl2, Ovol1/2 }\end{array}$ & Slug & $\begin{array}{l}\text { Arnoux et al., } 2005 \\
\text { Nieto et al., } 2016(1) \\
\text { Savagner et al., } 1997 \\
\text { Shirley et al., } 2010\end{array}$ \\
\hline
\end{tabular}

a(+) and (-) indicate positive and negative regulation of EMT, respectively.

Fig. 5: Comparison between EMT and partial EMT ${ }^{[34]}$.

\section{IV-EMT Importance:}

It is integral in: ${ }^{[1]}$

1. Embryonic development: Epithelium is the tissue phenotype of early embryos and a second tissue type, however, is produced by epithelialmesenchymal transformation. Both types can form all the three germ layers, ectoderm, mesoderm and endoderm

2. Wound healing.

3. Stem cell behavior.

4. Contributes pathologically to fibrosis and cancer progression.

\section{Types of EMT (Fig.6):}

EMT is often divided by biological context into three subtypes $^{[35]}$ :
1. Type I, which occurs during embryogenesis.

2. Type II, occurring during tissue repair.

3. Type III, which occurs during the metastatic spread of cancer

The three types of EMT have a shared outcome: the production of motile cells with a mesenchymal phenotype from otherwise classically adherent epithelial cells with apical-basal polarity. However, in contrast to Types I and III, Type II EMT is induced exclusively by damage and inflammation ${ }^{[36]}$. The type 2 EMTs associated with wound healing, tissue regeneration, and organ fibrosis are of a second type. In these, the program begins as part of a repair-associated event that normally generates fibroblasts and other related cells in order to reconstruct tissues following trauma and inflammatory injury. EMT has been proposed as the critical mechanism for the acquisition of malignant phenotypes by epithelial cancer cells ${ }^{[37]}$. 


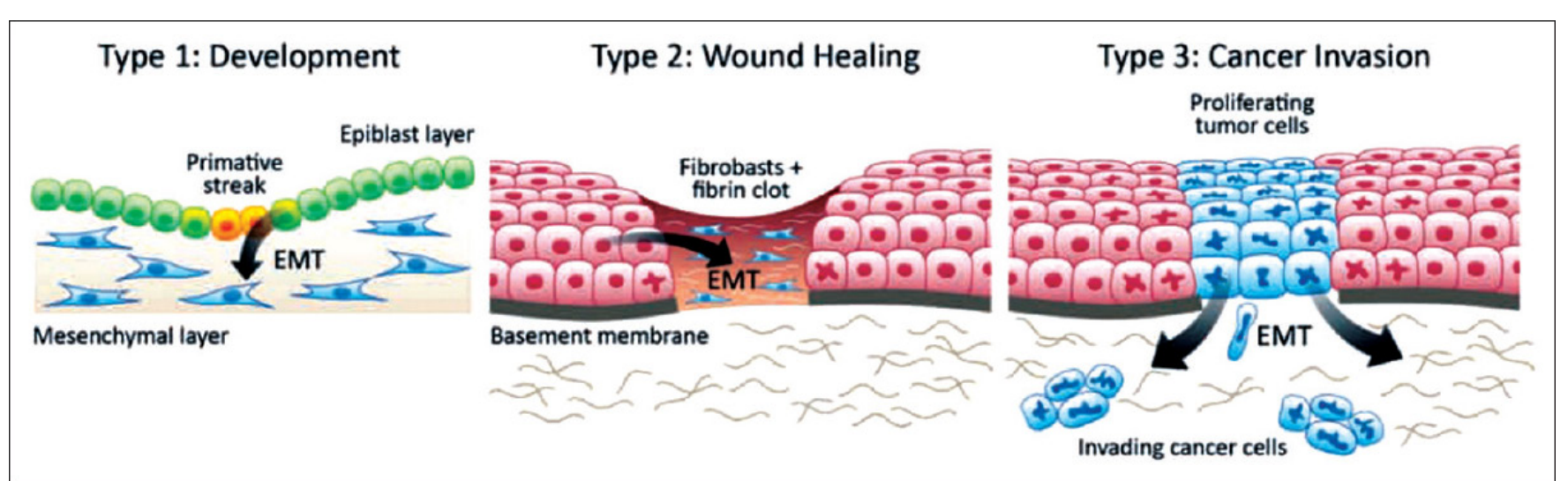

Fig. 6: Types of EMT ${ }^{[38]}$

\section{EMT Role in physiological tissue healing}

Several studies support the importance of proper execution of EMT in achieving successful tissue repair following injury and EMT was reported to play a role in both physiologic and pathologic healing.

\section{EMT and wound healing:}

Wound healing consists of several overlapping phases that involve an injury-induced inflammatory response which is associated with cellular proliferation, migration, and ECM remodeling ${ }^{[39]}$. In a thermal burn wound, myofibroblast formation and keratinocyte reepithelialization both rely on $\mathrm{EMT}^{[40]}$. (Fig.7)

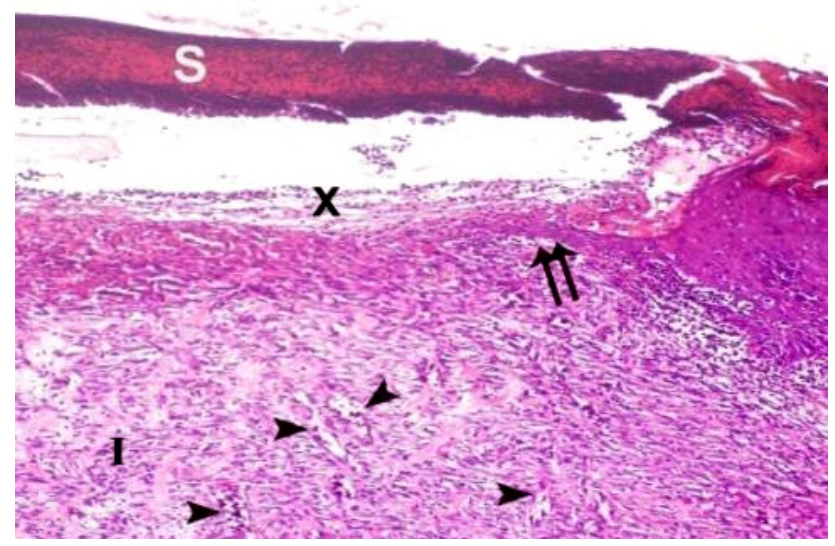

Fig. 7: EMT in skin wound healing ${ }^{[4]}$.

Of these processes, the one most reminiscent of EMT is the process of re-epithelialization, which has been termed "partial EMT"[25]. As discussed above, a hallmark of EMT is cell-cell dissociation and acquisition of motility, and during re-epithelialization keratinocytes at the wound edge lose their intercellular adhesions and migrate across the wound ${ }^{[42]}$. Specifically, these keratinocytes undergo changes in junctional complexes including reduction in desmosomes and adherens junctions, disruption of intermediate filaments, and cytoskeletal reorganization which results in the creation of intercellular gaps. These changes enable the keratinocytes to shift morphologically from cuboidal and stationary to flattened and migratory, with extended lamellipodia ${ }^{[43]}$. Zebrafish keratocytes in explant culture, which serve as a well-studied model of epithelial wound healing, were reported to display evidence of $\mathrm{EMT}^{[44]}$.

A recent study pioneered the use of intravital imaging of wound re-epithelialization in live mice to examine its spatiotemporal cellular dynamics (Park et al., 2017). This work not only re-enforced the accepted notion of spatially separated migratory and proliferative zones, but also discovered the existence of a so-called mixed zone where migration and proliferation co-exist. More specifically, cells change their shape from being polarized cuboidal to being more flattened and elongated with extended cytoplasmic projections (Fig.8) ${ }^{[34]}$.

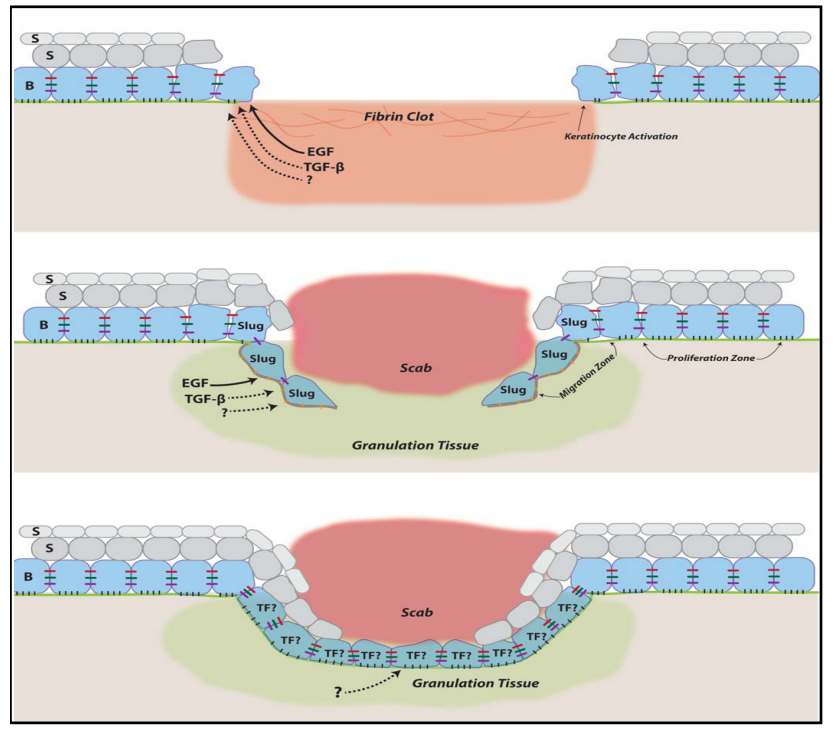

Fig.8: Partial EMT during cutaneous wound healing ${ }^{[34]}$. 
There is also evidence that myofibroblasts, the key players in the remodeling and maturation phase of wound healing, are derived from resident epithelial cells that have transformed through EMT to synthesize ECM components and to contract the wound bed, enabling approximation of the injured edges ${ }^{[45]}$. EMT is a component of cutaneous wound healing, during which otherwise stationary keratinocytes the resident skin epithelial cells - migrate across the wound bed to restore the epidermal barrier. For instance, during cutaneous wound healing epidermal keratinocytes undergo EMT by losing their adherent epithelial phenotype to become motile cells with a mesenchymal phenotype which migrate across the wound bed ${ }^{[26]}$.

Angiogenesis causes changes that allow for greater nutrient delivery over a long period of time. Capillaries are designed to provide maximum nutrient delivery efficiency, so an increase in the number of capillaries allows the network to deliver more nutrients in the same amount of time. A greater number of capillaries also allows for greater oxygen exchange in the network ${ }^{[46]}$.

Langerhans cells in skin express a broad range of epithelial- like adhesive molecules that permit the functional integration into the keratinocyte layer. This includes tight junction proteins, such as claudin-1 and ZO-1/Met signaling in skin resident DCs including LCs appears to be a critical determinant for maintaining normal immune function and as an important constituent that interlaces tissue regenerative functions with the appropriate immune responses that must be accomplished ${ }^{[47]}$.

\section{Cardiac repair:}

EMT is required to invade the regenerating myocardium and facilitate coronary neovascularization ${ }^{[48]}$. In postischemic injury, EndMT involves both the endocardium (the inner endothelial layer of the heart) and the microvascular endothelium of the heart ${ }^{[29]}$.It was reported that EMT and EndMT (endothelial mesenchymal transition) contribute to the pool of cardiovascular progenitor cells that maintain cardiac homeostasis ${ }^{[49]}$.

Besides the connection of mesenchymal transition to the emergence of stem cells, both EMT and EndMT are recognized as important mechanisms in the generation of the myofibroblasts that take part in fibrosis Therefore, it is possible that EMT and EndMT contribute to both cardiac regeneration and fibrosis after injury. In the last few years a number of studies have provided supportive evidence for this notion. ${ }^{[50]}$. For example, EndMT in the adult mouse heart gives rise to myofibroblasts that migrate and produce scar tissue in mouse models of pressure overload and chronic allograft rejection, recapitulating pathways that take place during formation of the atrioventricular cushions in the embryonic heart ${ }^{[29]}$. Moreover, isolated adult epicardial cells can undergo EMT in culture, differentiating to smooth muscle and endothelial cells ${ }^{[51]}$. Epicardial cells that express stem cell markers are induced after injury, migrate to the infarct, and contribute to both cardiac and vascular cell types that suggesting a function of epicardial cells that echoes their role in the regeneration of the adult zebrafish heart after partial resection ${ }^{[48]}$. Therefore, both endothelial and epicardial cells become activated after injury and give rise to cardiac, vascular and myofibroblast/smooth muscle cells; this seems similar to their capacity during development ${ }^{[49]}$. Myocardial injury indicates that a subpopulation of epicardial cells undergo EMT to regenerate the damaged epithelial cover and help establish new vasculature ${ }^{[52]}$.

\section{Different organs repair:}

There is additional evidence for EMT occurring during repair of organs other than the skin. During in vitrohealing of a breast (mammary) epithelial cell line, time-lapse microscopy indicated that EMT-associated vimentin was expressed in a migration-dependent fashion, such that vimentin was exclusively induced in actively migrating cells at the leading wound edge, which was accompanied by actin filament reorganization. Vimentin expression subsequently disappeared once wound closure was achieved ${ }^{[53]}$. During puberty, mammary gland tissue utilizes EMT to facilitate branching morphogenesis through which the developing gland migrates into and invades the fat pad $^{[54]}$.

Similarly, in a murine model of lacrimal gland injury, inflammation induced by interleukin-1 (IL-1) injection triggered the generation and migration of cells with mesenchymal features to the site of injury, which subsequently reverted to an epithelial phenotype once repair was complete ${ }^{[55]}$.

In addition, in each menstrual cycle the ovarian surface epithelium undergoes an EMT-like process during postovulatory wound healing. This EMT is induced by epidermal growth factor (EGF) and involves the activation of metalloproteases and of ILK and ERK kinases ${ }^{[56]}$.

\section{EMT Confers Stem Cell Properties:}

The cells that undergo EMT acquire stem celllike properties. EMT induces stem cell properties, preventing apoptosis and senescence and contributing to immunosuppression $^{[56]}$. EMT also yields adult cells with stem cell characteristics ${ }^{[57]}$. It is suggested that EMT causes cells into active and de-differentiated state and acquire stem cell-like characteristics ${ }^{[58]}$.

Although further analyses are necessary to determine whether EMT in normal tissues leads to the production of 
normal stem cells, this intriguing concept is supported by studies on embryonic stem (ES) cells and mesenchymal stem cells. EMT is observed at the periphery of human ES cell clusters grown on matrigels ${ }^{[59]}$. These undifferentiated mesenchymal cells are characterized by a shift from E- to $\mathrm{N}$-cadherin expression, the expression of Snail factors, vimentin, and metalloproteases. These cells also retain the expression of several totipotent transcription factors, including Oct-4 and Nanog, indicating that ES cells can adopt a mesenchymal phenotype without loosing their pluripotency ${ }^{[32]}$

Induction of an EMT in immortalized human mammary epithelial cells (HMLEs) results in the acquisition of mesenchymal traits, but in addition the expression of stem-cell markers, and an increased ability to form mammospheres, a property associated with mammary epithelial stem cells. Independent of this, stem cell-like cells isolated from HMLE cultures form mammospheres, differentiate into duct-like structures, and express markers similar to those of HMLEs that have undergone an EMT. Moreover, stem-like cells isolated either from mouse mammary glands, human reduction mammoplasty tissues, or mammary carcinomas express markers associated with cells that have undergone an EMT. Finally, transformed human mammary epithelial cells, that have undergone an EMT, forms mammospheres, soft agar colonies, and tumors more efficiently. These findings illustrate a direct link between the EMT and the gain of epithelial stem-cell properties $^{[57]}$.

Conversely, it is suggested that EMT causes cells into active and de-differentiated state and acquire stem cell-like characteristics $^{[58]}$. EMT also contributes to tissue repair, but it can adversely cause organ fibrosis and promote carcinoma progression through a variety of mechanisms ${ }^{[56]}$.

\section{Role of EMT in pathological healing}

1. Wound scaring:

While EMT is necessary for proper re-epithelialization and extracellular matrix deposition, uncontrolled continued transition from epithelial cells to myofibroblasts may result in fibrosis. EMT in generating myofibroblasts from resident epithelial cells during the maturation phase of wound healing. Sustained EMT was reported to be a key mechanism underlying the fibrotic pathology of multiple organs including the skin. The role of EMT in pathophysiology of renal, pulmonary, cardiac and liver fibrosis, cutaneous scleroderma, and impaired wound healing are also discussed. In the setting of organ fibrosis, type 2 EMTs can continue to respond to ongoing inflammation, leading eventually to organ destruction. Tissue fibrosis is in essence an unabated form of wound healing due to persistent inflammation. However, EMT also plays a role in the development of scarring and fibrosis, as the matrix-producing myofibroblast arises from cells of epithelial lineage in response to injury but is pathologically sustained instead of undergoing MET or apoptosis. However, pathologically prolonged myofibroblast activity results in fibrogenesis ${ }^{[35]}$.

EMT Characteristics in Hypertrophic Scars Are Associated with Persistent Inflammation and Fibrosis:

In normal wound healing, many myofibroblasts undergo apoptosis and disappear once re-epithelialization is complete ${ }^{[60]}$. An association was previously reported between EMT and inflammation and fibrogenesis in human hypertrophic scars. An active hypertrophic scar is denoted by the presence of infiltrating lymphocytes and numerous antigen-presenting cells ${ }^{[61]}$. Active scars are also characterized by their elevated appearance consisting of thick epithelium and condensed dermis with ample myofibroblasts and interstitial matrix fibers. Among the inflammatory group, TNF- $\alpha$, MMP-9, and MMP-13 were significantly increased 2-, 14-, and 8-fold, respectively, in the scars compared normal skin. The classic fibrotic markers, type-I collagen and $\alpha$-smooth muscle actin, were elevated 8- and 2-fold, respectively, in the scars versus normal skin. Finally, the EMT-related transcription factors slug and twist-1 were significantly expressed in the scars. However, E-cadherin, which is down-regulated in EMT of many epithelial cells cultured in vitro, is not significantly reduced at global level in the scar tissues, the fact that is explained by epithelial hypertrophy, which may compensate globally for the loss of E-cadherin in defined EMT locus. In contrast, gain of mesenchymal markers such as vimentin and $\mathrm{N}$-cadherin was clearly increased in the scars. Together, these results demonstrate a clear association between unresolved inflammation and persistent EMT features in the developing scars, indicating a possible causal relationship. In this way, a link was demonstrated between unresolved inflammation and the development EMT characteristics during fibrogenesis in hypertrophic scar tissue in vivo ${ }^{[26]}$.

Scleroderma $(\mathrm{Sc})$ is a systemic disorder characterized by autoimmunity, chronic inflammation, vasculopathy and extensive skin and organ fibrosis of unknown etiology ${ }^{[62]}$. In Sc, early vascular injury precedes fibrosis, and as with renal fibrosis, the persistently activated myofibroblast drives TGF $\beta$-induced gene expression and increases profibrotic cytokine and protease production. Although the origin of the myofibroblasts in Sc fibrotic skin is unknown, studies have once again indicated that the EMT process is one possible source ${ }^{[27]}$.

\section{Cardiac and other organs fibrosis (Fig. 9):}

Organ fibrosis, which occurs in a number of epithelial tissues, is mediated by inflammatory cells and fibroblasts that release a variety of inflammatory signals as well as 
components of a complex ECM that includes collagens, laminins, elastin, and tenacins. More specifically, such EMTs are found to be associated with fibrosis occurring in kidney, liver, lung, and intestine ${ }^{[28,29]}$. Some of the earliest proof of this came from the study of transgenic mice bearing germ-line reporter genes whose expression was driven by epithelial cell-specific promoters. The behavior of these reporters provided direct evidence for epithelial cells serving, via EMTs, as important precursors of the fibroblasts that arise during the course of organ fibrosis ${ }^{[30]}$.

Such cells continued to exhibit epithelial-specific morphology and molecular markers, such as cytokeratin and E-cadherin, but showed concomitant expression of the FSP1 mesenchymal marker and $\alpha$-SMA. Such cells are likely to represent the intermediate stages of EMT, when epithelial markers continue to be expressed but new mesenchymal markers have already been acquired. The behavior of these cells provided one of the first indications that epithelial cells under inflammatory stresses can advance to various extents through an EMT, creating the notion of "partial EMTs"[38].

Recent experiments in mice have demonstrated that endothelial cells associated with the microvasculature can also contribute to the formation of mesenchymal cells during the course of fibrosis, doing so via an analogous process known as EndMT ${ }^{[63]}$.

In cardiac fibrosis associated with post-ischemic injury of the heart, EndMT, which involves both the endocardium (the inner endothelial layer of the heart) and the microvascular endothelium of the heart, has been demonstrated to play a key role in contributing to the emergence of newly formed fibroblasts ${ }^{[29]}$. In tissue culture models of EndMT, TGF- $\beta 1$ induces EndMT of capillary endothelial cells and the loss of endothelial markers, such CD31 and integrin $\alpha \mathrm{V} \beta 3$, as well as the acquisition of fibroblast- and myofibroblastspecific markers such as FSP1, $\alpha$-SMA, DDR2, collagen $\mathrm{I}$, and vimentin. While not yet documented, it is plausible that many of the molecular regulators of EMTs also play critical roles in orchestrating EndMTs ${ }^{[38]}$.

Type 2 EMTs are associated with organ fibrosis and regeneration occurring in the liver, lung, kidney and intestine. FSP $1, \alpha$-SMA and collagen 1 are the characterized markers of the mesenchymal products generated by the EMTs during the development of organ fibrosis ${ }^{[64]}$. The aforementioned markers, along with vimentin, desmin and discoidin domain receptor 2 (DDR2), have been used to distinguish the epithelial cells that are undergoing EMTs in response to ongoing inflammation. With the development of EMTs, these cells continue to exhibit epithelial-specific morphology and molecular markers, such as E-cadherin and cytokeratin, but showed concomitant expression of FSP 1 and $\alpha-$ SMA $^{[31]}$.
Another source of myofibroblasts during fibrosis has been hypothesized to originate from endothelial cells by a process of endothelial-mesenchymal transition (EndoMT).

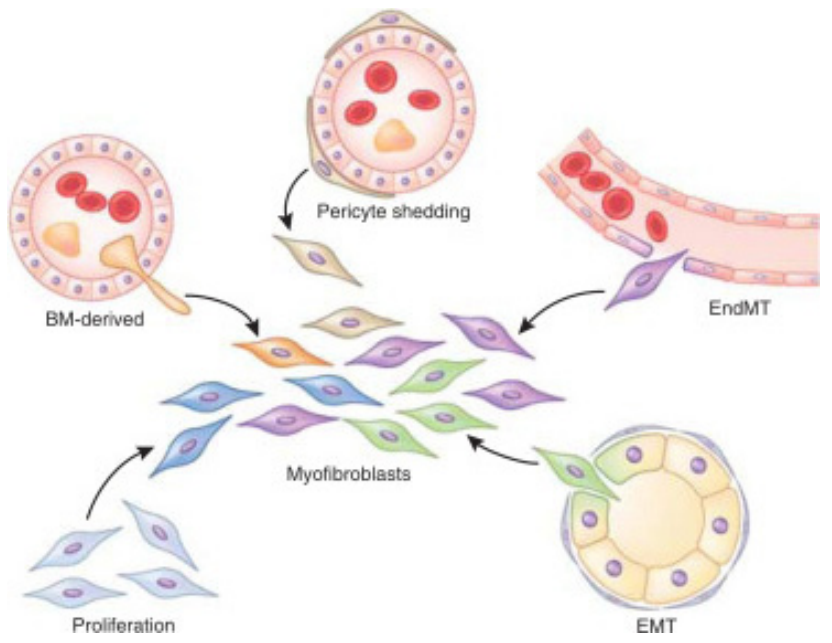

Fig. 9: EMT and organs fibrosis ${ }^{[65]}$.

This event has been characterized in animal models of fibrosis; however, similar phenomena in human fibrosis patients have not yet been well characterized ${ }^{[66]}$.

Different sources of fibroblasts in organ fibrosis. Four possible mechanisms are depicted. One study suggests that about $12 \%$ of fibroblasts are from bone marrow, about $30 \%$ can arise via local EMT involving tubular epithelial cells under inflammatory stress, and about $35 \%$ are from EndMT. The remaining percentage likely emerge via proliferation of the resident fibroblasts and other still unidentified sources (Fig. 8) ${ }^{[67]}$.

$\approx 30 \%$ to $50 \%$ of fibroblasts coexpressed the EC marker CD31 along with markers of myofibroblasts and fibroblasts, including fibroblast-specific protein-1 and $\alpha$-smooth muscle actin. Lineage tracing experiments confirmed the EC origin of these cells.16 More recent work has suggested that only $\approx 10 \%$ of the myofibroblasts present in kidney fibrosis derive from an EndoMT, whereas the remainder come from proliferation of local fibroblasts and differentiation from bone marrow cells.17 Other studies, however, have suggested that these fibroblasts may be derived from pericytes.18 It should be borne in mind, however, that these are all mouse studies and strainspecific differences are always a possibility. Other fibrotic diseases where EndoMT has been implicated as a source of fibroblasts/stromal cells include intestinal fibrosis 19 and scleroderma $^{[32]}$.

In fibrotic tissues, myofibroblasts accumulate and secrete an excessive amount of collagen that is deposited as fibers, thereby compromising organ function and leading to its failure. Fibrosis had been thought to originate through 
the pathological activation of interstitial fibroblasts that convert to myofibroblasts to form the fibrotic collagen network. However, elegant cell tracing studies have shown that a significant portion of these myofibroblasts arise from the conversion of epithelial cells through an EMT process ${ }^{[68]}$. Initially demonstrated in differentiated cells of renal tubules and ducts, it is now clear that lens epithelium, endothelium, hepatocytes, and cardiomyocytes can all undergo EMT and contribute significantly to tissue fibrosis. Indeed, lineage-tracing in transgenic mice also indicates that hepatocytes undergo EMT during CCL4induced liver fibrosis ${ }^{[2]}$, as do the alveolar epithelial cells during the pulmonary fibrosis induced by TGF $\beta^{[28]}$. Interestingly, hepatocytes derived from cirrhotic livers also display characteristics of EMT, which has implications for the progression to hepatocellular carcinoma ${ }^{[69]}$.

EMT involving transformation of endothelial cells into mesenchymal cells is evident during cardiac and renal fibrosis $\left(\right.$ EndMT ${ }^{[29]}$. Mesothelial cells are also converted to mesenchyme in patients that receive ambulatory peritoneal dialysis and that develop peritoneal fibrosis ${ }^{[70]}$.

Type 2 epithelial to mesenchymal transition (EMT) is known as one of the key mechanisms of intestinal fibrosis. Activated myofibroblasts, which are key effector cells in intestinal fibrosis and produce excessive amounts of collagen-rich extracellular matrix, can be derived from epithelial cells by EMT $^{[71]}$.

\section{EMT and cataract:}

Furthermore, the EMT undergone by lens epithelial cells contributes to capsular opacification after cataract surgery ${ }^{[72]}$.There is compelling evidence implicating epithelial-mesenchymal transition (EMT) in the pathogenesis of anterior subcapsular cataract (ASC) and PCO. During EMT, polarized lens epithelial cells (LECs) relinquish their cobblestone morphology and transdifferentiate into spindle-shaped myofibroblastic cells that elongate and migrate across the lens capsule. Transforming growth factor- $\beta$ (TGF $\beta$ ) has been studied extensively as a key inducer of this lens EMT in vitro ${ }^{[73]}$.

\section{Endometriosis:}

Estrogen induces an epithelial-mesenchymal transition (EMT) during implantation of the ectopic endometrium, which consists of stromal and epithelial cells. EMT is a process whereby epithelial cells convert to a mesenchymal phenotype, and EMT may be essential for the migration, invasion, and relocalization of epithelial cells ${ }^{[74]}$. EMT can be induced by a number of signals, including the acute stress response ${ }^{[75]}$. Stimulating signals such as hypoxia and estrogen activate the origination and migration of endometriotic lesions. Basic pathways of EMT, such as TGF- $\beta$ and Wnt, could provide potential therapeutic approach to inhibit endometriotic cell motility and invasivenes ${ }^{[76]}$.

\section{MET (Reversed EMT) in healing}

EMT is now considered a transition suggesting a transient and reversible process ${ }^{[3]}$. The reverse process of EMT is termed mesenchymal-to-epithelial transition (MET). Conceivably, the adhesive and cytoskeletal changes that occur in the leading edge must be kept in check so that migrating epidermal cells are able to eventually resume their full epithelial state to execute a terminal differentiation program to regenerate a stratified epithelium (Fig. 10) ${ }^{[77]}$.

Epithelial-to-mesenchymal transition (EMT) is a reversible process that controls the phenotypic changes due to cell mobility ${ }^{[78]}$, Experimental evidence has shown that the removal of EMT inducers results in the reversal of EMT and EMT-associated phenotype ${ }^{[3]}$. Reverse epithelial-mesenchymal transition was reported to contribute to the regain of drug sensitivity in lung cancer cells $^{[79]}$

Type 1 EMTs can generate mesenchymal cells (primary mesenchyme) that have the potential to subsequently undergo a MET to generate secondary epithelia ${ }^{[58]}$.

The undergoing of MET or apoptosis are important during wound healing to prevent the development of scarring and fibrosis in response to injury as the persistence of inflammation and EMT leads to the development of active scars which is characterized by their elevated appearance consisting of thick epithelium and condensed dermis with ample myofibroblasts and interstitial matrix fibers ${ }^{[26]}$. Indeed, E-cadherin returns to normal levels soon after the two migrating fronts meet ${ }^{[77]}$. Moreover, the expression of genes within the leading edge signature decreases as wound re-epithelialization progresses, and disappears upon fusion of the two edges whereas proliferation is resumed at the wound center ${ }^{[27]}$. Furthermore, loss of a desmosomal component Perp leads to impaired re-epithelialization due to enhanced keratinocyte migration while proliferation is unaffected ${ }^{[80]}$. These findings implicate the transient and reversible nature of the molecular/cellular events that occur during wound reepithelialization. However, a systematic comparison between the reverse events in the neoepidermis and MET has not yet been performed ${ }^{[34]}$. However, the depletion of vimentin delays wound healing by mesenchymal fibroblasts trans-differentiating into epithelia through $\mathrm{MET}^{[58]}$.

MET was reported to has a role in endometrial regeneration and have important implications for proliferative diseases of the endometrium ${ }^{[81,82]}$.

MET is involved in stem cell inactivation, cell polarization and differentiation. This process is associated with a reduction of vimentin and accumulation of CK8/18 in stem cells. Furthermore, the variation of vimentin in stem cells is an indicator of cell proliferative activity ${ }^{[58]}$. 


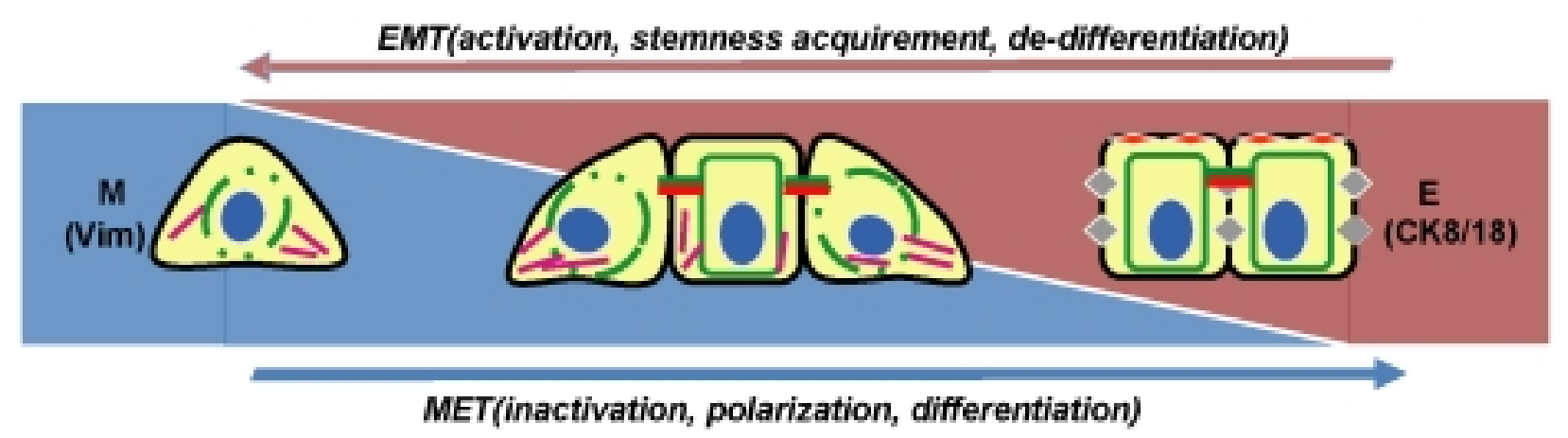

Fig. 10: Mesenchymal- epithelial transition ${ }^{[58]}$.

Systemic administration of recombinant BMP-7 to mice with severe fibrosis resulted in reversal of EMT and repair of damaged epithelial structures, with repopulation of healthy epithelial cells, all presumably mediated via a $\mathrm{MET}^{[62]}$.

Metastasizing cancer cells must shed their mesenchymal phenotype via a MET during the course of secondary tumor formation this behavior with the proposed role of EMT as a facilitator of metastatic dissemination requires the additional notion that metastasizing cancer cells must shed their mesenchymal phenotype via a MET during the course of secondary tumor formation ${ }^{[65]}$. These considerations indicate that induction of an EMT is likely to be a centrally important mechanism for the progression of carcinomas to a metastatic stage and implicates MET during the subsequent colonization process ${ }^{[38]}$.

\section{Molecular mechanisms of EMT}

A better understanding of epithelial plasticity regulation during wound healing has important clinical implications. Managing chronic wounds represents major health care costs, and our ability to manipulate such plasticity holds promise in improving

wound repair in human patients. Insights from wound studies are likely also applicable to cancer research, where EMT has been considered a major contributing factor to metastasis and/or chemoresistance, and to tissue fibrosis, which is shown to be associated with enhanced/prolonged $\mathrm{EMT}^{[3]}$.

\section{Growth factors: (Fig. 11)}

Several growth factors were reported to be common in both wound healing and EMT, such as fibroblast growth factor (FGF), hepatocyte growth factor (HGF), epidermal growth factor (EGF) and transforming growth factor-beta $(\mathrm{TGF} \beta)$ and keratinocyte growth factor $(\mathrm{KGF})^{[35 \text { and39]. }}$.

Signaling in the wound bed is a complicated and intertwining affair involving epidermal, dermal, and immune cells, as well as both paracrine and autocrine mechanisms. Platelets and neutrophils represent some of the key initial signaling sources that release factors to activate/recruit fibroblasts and keratinocytes ${ }^{[28]}$. In addition, growth factors Wnt, Hedgehog (Hh), and Notch like and signaling were reported to induce $\mathrm{EMT}^{[34]}$.

During injury-triggered migration, keratocytes feature loss of epithelial keratins and E-cadherin accompanied by gain of mesenchymal markers vimentin and N-cadherin. Moreover, explanted zebrafish keratocytes exhibit EMTlike morphologic changes including actin cytoskeletal rearrangements, disassembly of cellular sheets, and flattened cells. Interestingly, cell motility in this model appears to be driven in part by TGF $\beta 1^{[9]}$ which is a known trigger of EMT.

Furthermore, treatment of ex vivo human skin with inflammatory cytokines tumor necrosis factor- alpha $(\mathrm{TNF} \alpha)$ and TGF $\beta$ induced an EMT-positive cell population. Primary keratinocytes treated similarly displayed morphologic cellular elongation as well as an enhanced migratory phenotype which was reversible following removal of cytokine stimuli. As such, injuryinducible mobilization of epithelial cells involving $\mathrm{TNF} \alpha$ and bone morphogenetic protein (BMP)-2 produced a mesenchymal phenotype in migrating keratinocytes ${ }^{[26]}$.

FGF, is increased in the acute wound and plays a role in granulation tissue formation, epithelialization, and tissue remodeling ${ }^{[83]}$. In vitro studies have shown that activation of the FGF receptor increases keratinocyte and fibroblast motility ${ }^{[84]}$, and stimulates fibroblasts to produce collagenase $^{[85]}$. The FGF family is also induced during EMT, with the role to ensure that epithelial cells adopt a mesenchymal phenotype through classic effects such as down-regulation of E-cadherin and catenins and induction of mesenchymal MMPs ${ }^{[86]}$.

EGF signaling leads to the activation of a number of converging signaling pathways promoting keratinocyte migration and proliferation ${ }^{[87]}$. EGF also aids to accomplish EMT by down- regulating E-cadherin via E-cadherin internalization.

HGF signaling is an additional example of the wound 
healing - EMT crosstalk. HGF, mainly produced by fibroblasts, exerts its function by binding to its tyrosine kinase receptor c-Met (mesenchymal epithelial transition factor, or HGFR), which is expressed on the surface of keratinocytes $^{[88]}$. Both HGF and c-Met are upregulated during wound healing and promote granulation tissue formation and neoangiogenesis ${ }^{[89]}$.

TGF $\beta$ progresses via two pathways, SMAD-dependent and SMAD-independent. In SMAD dependent pathways, the TGF $\beta$ cell surface receptors (known as TGF $\beta$ receptors type II) are activated by ligand and phosphorylate the transmembrane kinases (TGF $\beta$ receptor type I), which then forms a SMAD complex; this complex can enter the nucleus, subsequently activating or inhibiting transcription factors important for either wound healing or EMT. In wound healing, TGF $\beta 1$ play important roles in inflammation, angiogenesis, re-epithelialization, and connective tissue regeneration ${ }^{[00]}$.

Other developmental signaling pathways such as Wnt, Hh, and Notch have also been implicated in wound healing ${ }^{[91]}$. A functional involvement of Wnt signaling has been shown for hair follicle regeneration in large wounds ${ }^{[92]}$.

Osteopontin (OPN) is a secreted glycoprotein also known as secreted phosphoprotein that has recently been implicated in all three processes that involve EMT: embryogenesis, wound healing/fibrosis, and tumorigenesis. OPN is known to bind to multiple integrin receptors. With regard to wound healing, OPN is upregulated during the inflammatory phase and plays several key roles in wound healing. TGF- $\beta$ is a key cytokines involved in many elements of wound healing, including the induction EMT via many pathways. OPN appears to play an important role in TGF- $\beta$-dependent processes and likely is involved in
TGF- $\beta$-mediated EMT ${ }^{[40]}$.

The intracellular calcium signal was reported to play an important role in the induction of EMT in human breast cancer cells. Manipulation of calcium-signaling pathways controlling EMT induction in cancer cells may therefore be an important therapeutic strategy for preventing metastases ${ }^{[93]}$.

After the first 2 to 3 days of the treatment of TNF- $\alpha$ or TGF- $\beta$, epidermal keratinocytes isolated from adult human skin, cells displayed spindle-shaped body and "long-armed" intercellular connections, demonstrating morphological plasticity of epithelia cells under stress. this transition of cell morphology from polygonal to spindle shapes is reversible. In the prolonged exposure to the cytokines for 4 to 5 days, the epithelial cells were scattered from patched clones and stably express mesenchymalmarkers. Under TNF- $\alpha$ or TGF- $\beta$, most of the epithelial cells expressed vimentin, an intermediate filamentous cytoskeleton involved in migration of mesenchymal cells $^{[26]}$

\section{Transcription factors: (Fig.12)}

This switch in cell differentiation and behavior during EMT, is mediated by key transcription factors, including SNAIL, zinc-finger E-box-binding (ZEB) and basic helixloop-helix transcription factors, the functions of which are finely regulated at the transcriptional, translational and post-translational levels ${ }^{[1]}$

The EMT-promoting transcription factors includes Snail (SNAI1), Slug (SNAI2), Zeb1, Zeb2, and Twist, and EMT-inhibiting transcription factors, such as Grhl2, Ovol1, and Ovol2 ${ }^{[3,94]}$. Wound healing in mouse embryos is distinctly different from that in adult animals, particularly in

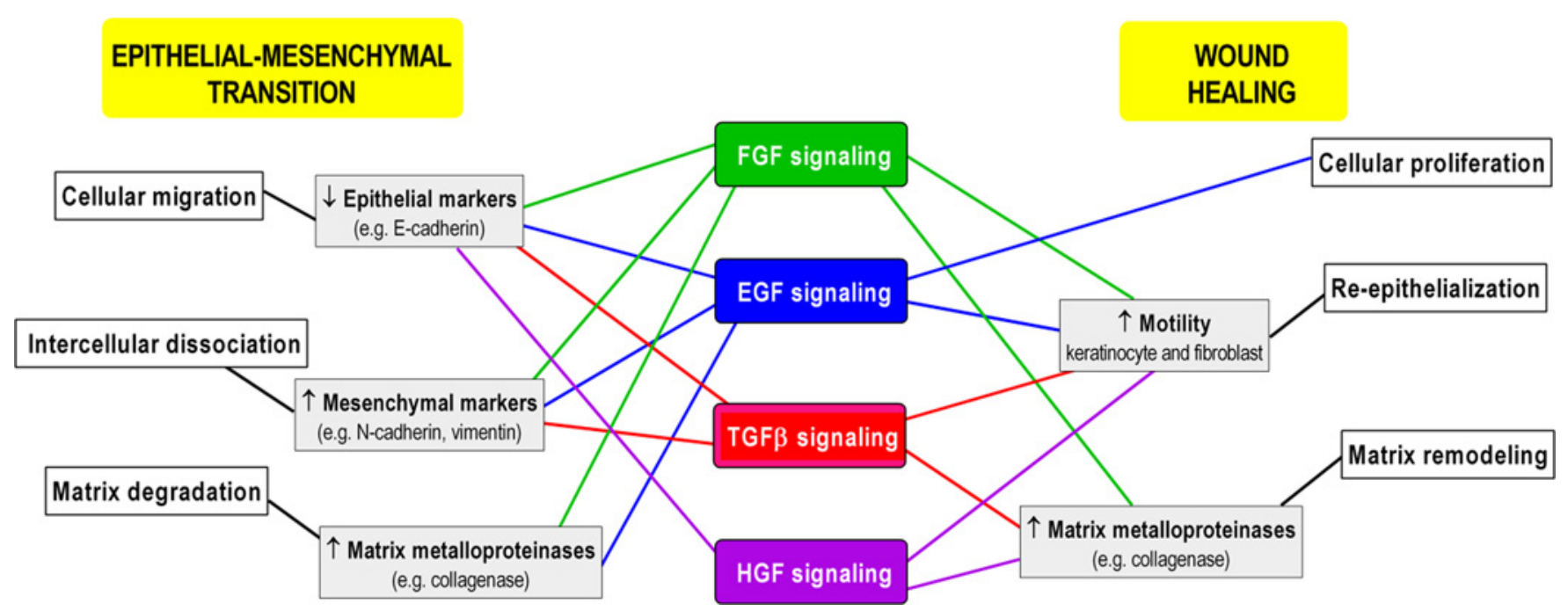

Fig. 11: Growth factors for EMT (Stone et al., 2016). 
that embryonic wounds heal perfectly without scarring ${ }^{[95]}$. A possible explanation for regeneration in embryos vs. scar formation in adults is the absence of inflammation during embryonic wound healing in mice ${ }^{[96]}$.

To begin with, HGF can regulate master EMT transcription factor SNAIL1 (which decreases E-cadherin) and Slug (which decreases desmoplakins) aiding in the breakdown of intercellular adhesions ${ }^{[97]}$. To start with, the EMT transcription factor Slug has been implicated in the process of re-epithelialization in numerous studies. Healing of excisional wounds is impaired in Slug knockout mice almost twofold in comparison to wild-type controls ${ }^{[98]}$. In ex vivo skin explants from Slug null mice, epithelial cell outgrowth is also severely impaired, again indicating compromised motilityy ${ }^{[99]}$. Indeed, Slug expression is elevated in wild-type keratinocytes at the edges of murine wounds in vivo ${ }^{[100]}$ and its expression specifically increases in the actively migrating mouse keratinocytes ${ }^{[101]}$.

TGF $\beta$ and SMAD complexes induce SNAIL1 expression, and themselves are potent downregulators of E-cadherin, occludin, and other epithelial phenotypic markers, while promoting mesenchymal markers such as vimentin and $\mathrm{N}$-cadherin ${ }^{[102]}$. Mechanistically, Slug regulates keratinocyte motility during re-epithelialization by repressing E-cadherin, leading to decreased cell-cell adhesion $^{[103]}$.

The epidermal growth factor receptor (EGFR) signaling pathway that is integral to re-epithelialization in physiologic wound healing may be the master regulator of EMT/Slug-mediated effects, since EGFR ligands stimulate the expression of Slug as well as subsequent migration in keratinocytes in a process that is mediated by Erk $5^{[99]}$.

Foxn1, a potent mammalian wound healing factor, also appears to be involved in EMT-driven re-epithelialization during repair, as evidenced by studies in Foxn1 transgenic mice. In these mice, the induction of EMT postwounding was demonstrated though the upregulation of EMT transcriptional regulator Snail1, increased MMP9 expression, presence of vimentin + /E-cadherin + cells, and migratory keratinocytes at the wound edge expressed Foxn1 which co-localized with Snail ${ }^{[104]}$.

Similarly, antimicrobial peptides shown to enhance wound healing concurrently induce Slug at the edge of wounded $\mathrm{HaCaTs}^{[105]}$. These data reinforced the idea that biological responses to TGF- $\beta$ result from extensive cross talk of different signaling pathways. They further argue that harnessing those networks, such as the endocytic matrix that integrates multiple cellular functions is instrumental to achieve plasticity of cell identity, as typified by $\mathrm{EMT}^{[106]}$. Moreover, Slug is the only well-known EMT-inducing transcription factor for which a function in wound reepithelialization has been shown $n^{[3,29]}$.

Wnt signaling is a central regulatory knot that controls two of the landmark events in the biology of stem cells, EMT and cell cycle regulation. Interestingly, Wnt signaling also regulates fibrosis, controlling the generation of mesenchymal cells by EMT as well as their proliferation and motility. Collectively, these data suggest that proper modulation of Wnt signaling is key in balancing cardiac fibrosis and regeneration after injury ${ }^{[49]}$.

Snail is associated with the activation of immunosuppressive cytokines. EMT process in general, can accelerate cancer metastasis not only by increasing invasion, but also by acting on multiple immunosuppression and immunoresistance mechanisms, reflecting an alteration in the response of the host to the tumor. Thus, therapies directed to interfere with EMT might not only be antiinvasive but also able to restore immunocompetence in patients $^{[32]}$. 

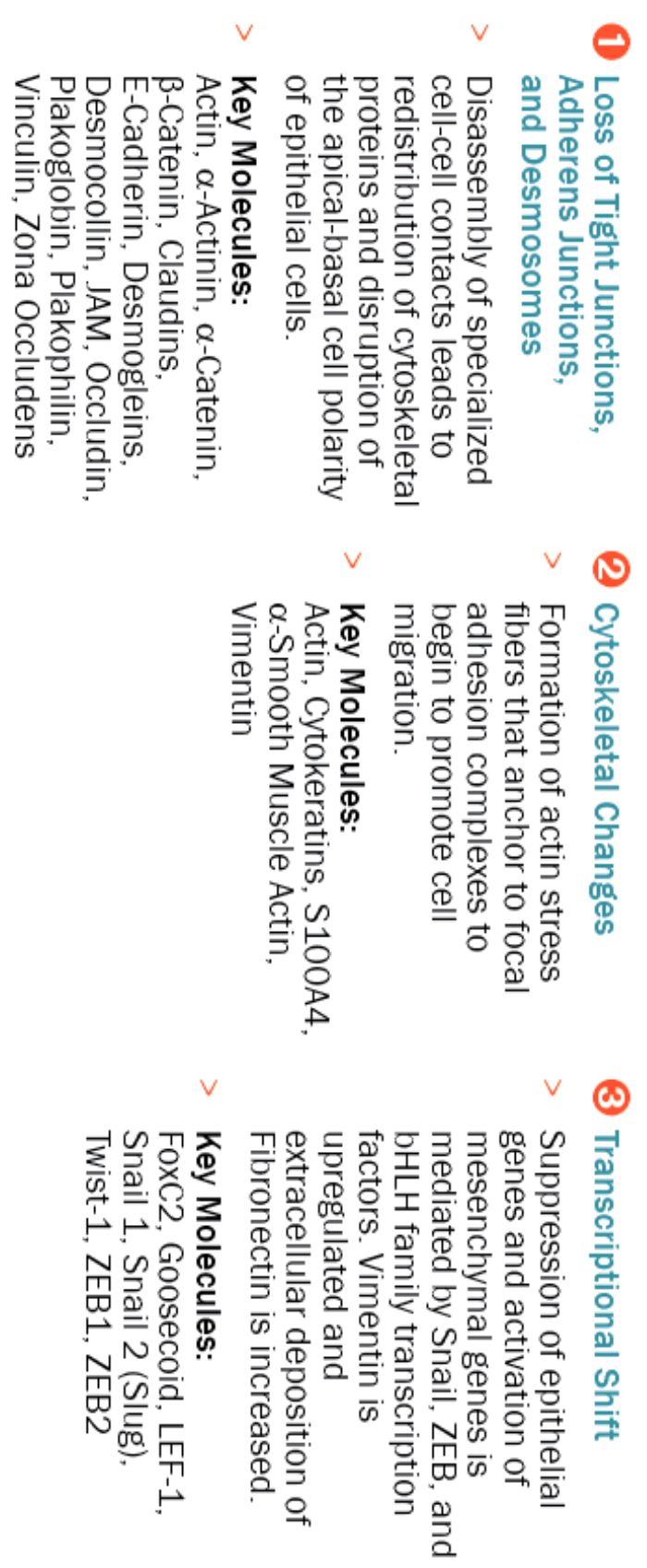

()

(2)
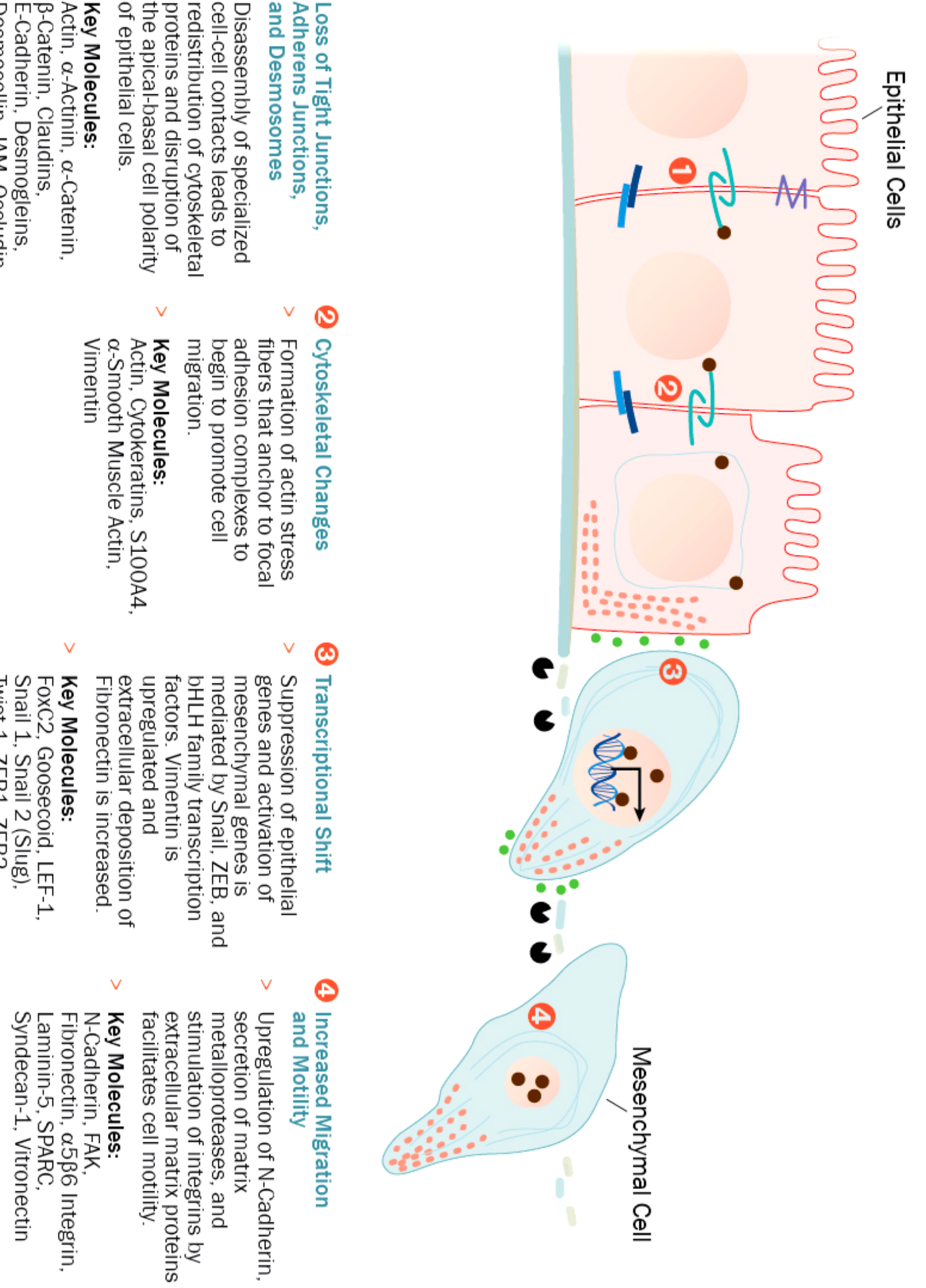

Fig. 12: EMT molecular mechanisms (https://www.regmednet.com/users/19900-bio-techne/posts/13565-getting-to-know-emt-reepithelialization-during-wound-healing) 


\section{EMT markers:}

In the prolonged exposure to the cytokines for 4 to 5 days, under TNF- $\alpha$ or TGF- $\beta$, most of the epithelial cells expressed mesenchymal-markers vimentin, an intermediate filamentous cytoskeleton involved in migration of mesenchymal cells. Vimentin fibers were observed in the perinuclear regions, whereas cortactin, an organizer of filamentous actin, was found in the outreaching lamellapodia. These features are prominent characteristics of mesenchymal cells, demonstrating plasticity of the epithelial cells under the injury signals. Induction of vimentin protein was also measured by Western blot analysis, which is consistent with its mRNA levels. Expression of MMPs is another benchmark of EMT to facilitate cell migration. Expression of multiple MMPs by the keratinocytes under the injury signals, such as TNF- $\alpha$ and IL- 1 , in the keratinocytes may weaken the intercellular adhesions, and provoke ECM degradation to facilitate cell migration ${ }^{[107]}$.

Using the association of vimentin and $\beta$-catenin was suggest for the diagnosis of EMT in renal pathology because it is both sensitive and prognostic, thus satisfying the properties required for a screening test ${ }^{[108]}$.

\section{6- Methods to study EMT}

Cell Characterization (Fig. 13): A critical step to studying EMT is being able to clearly distinguish epithelial and mesenchymal phenotypes. Antibodies are readily available against cell surface markers and transcription factors specific to epithelial and mesenchymal phenotypes. A great reference for these markers and corresponding antibodies can be found at Novus Biologicals website. To make it more simple, one-step simultaneous immunofluorescence staining of human epithelial and mesenchymal markers can be performed with the aptly named Human EMT 3-Color Immunocytochemistry Kit from R\&D Systems, which features a combination of fluorphore-conjugated antibodies against E-Cadherin (epithelial marker), Snail and Vimentin (mesenchymal markers $)^{[1]}$.

Fibroblast-specific protein 1 (FSP1; also known as S100A4 and MTS-1), an S100 class of cytoskeletal protein, $\alpha$-SMA, and collagen I have provided reliable markers to characterize the mesenchymal products generated by the EMTs that occur during the development of fibrosis in various organs ${ }^{[48,49,51]}$. These markers, along with discoidin domain receptor tyrosine kinase 2 (DDR2), vimentin, and desmin, have been used to identify epithelial cells of the kidney, liver, lung, and intestine that are in the midst of undergoing an EMT associated with chronic inflammation ${ }^{[38]}$.

Functional Assays (Fig. 14): A key aspect of EMT as it relates to wound healing is the migration of mesenchymal- like cells into the injury site of injury. Chemotactic assays are a standardized and effective way to monitor the migration of mesenchymal stem cells after EMT induction. These assays enable researchers to assess the efficiency of EMT induction as well as investigate the mechanisms underlying re-epithelialization through migration $^{[109]}$.
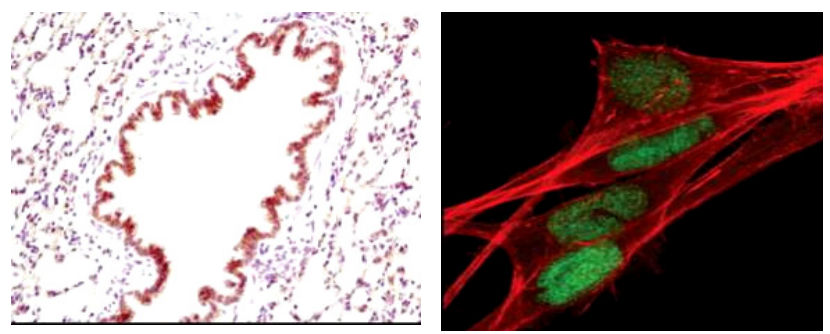

Fig. 13: Cell Characterization

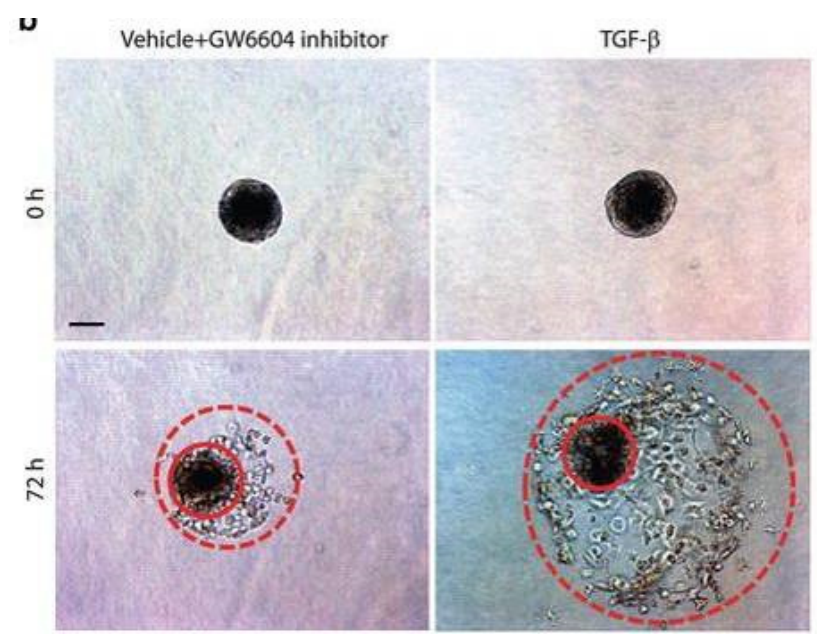

Fig. 14: Functional Assays

\section{Therapeutic application of EMT}

\section{EMT induction:}

Nevertheless, assessing the presence of the classic EMT biomarkers in non-healing tissues and organs in vivo will be critical to define the role for EMT in initiating and sustaining a poor healing response, and may represent a way forward to potential targeting of EMT as a novel and global therapeutic approach for difficult-to-treat wounds ${ }^{[35]}$.

Several diseases, such as ischemic chronic wounds, are the result of failure or insufficient blood vessel formation and may be treated by a local expansion of blood vessels, thus bringing new nutrients to the site, facilitating repair. Other diseases, such as age-related macular degeneration, may be created by a local expansion of blood vessels, interfering with normal physiological processes ${ }^{[110]}$.

Under physiological and pathological conditions, EMT can be induced by extrinsic factors, such as growth factors and cytokines, or intrinsic regulators, such as Twist1, 
Snail and Slug. and a significant proportion of cancer cells exhibit intermediate states of EMT or hybrid EMT ${ }^{[11]}$.

Lipocalin 2 (LCN2) which is an estrogen-dependent, acute-phase protein is an induced stressor that promotes the epithelial-mesenchymal transition (EMT) ${ }^{[12]}$.

Cell culture models of EMT are employed to understand the biology of EMT and for identifying and evaluating novel prognostic markers and therapeutics for fibrotic diseases, wound healing, and metastasis. The ability to induce EMT in vitro typically requires TGFbeta stimulation or labor-intensive genetic modification. While TGF-beta stimulation is the most common method used to induce EMT, it is not always sufficient. To more reliably induce EMT, specialized cocktails of recombinant proteins and neutralizing antibodies can be utilized. One such cocktail is the StemXVivo ${ }^{\circledR}$ EMT Induction Media Supplement from R\&D Systems. This supplement, which contains an optimized cocktail of proteins and antibodies, is designed for straightforward and quick induction of EMT. (https://www.rndsystems.com/products/epithelialmesenchymal-transition-products).

\section{EMT inhibition:}

Because of its potent role of EMT in pathogenesis of fibrotic diseases, detection of EMT in biopsy specimens could be useful diagnostically, and anti-EMT therapy has emerged as a target for drug development ${ }^{[108]}$. Inhibition of the TGF- $\beta$ receptor kinase using its specific inhibitor SB431542 blocks TGF- $\beta$-induced EMT in pancreatic cancer cells ${ }^{[113]}$. It was reported that the fibrosis response can be reversed in vivo by inhibition of Snaill expression in mouse models of kidney injury ${ }^{[114]}$.

Cells undergoing EMT show a feature similar to cancer stem cells (CSCs), such as an increase in drug efflux pumps and prevent apoptosis and senescence. Therefore, targeting EMT has been considered a novel opportunity to overcome cancer drug resistance ${ }^{[115,116]}$. The therapies directed to interfere with EMT might were reported to not only be anti-invasive but also able to restore immunocompetence in patients ${ }^{[32]}$.

While TGF $\beta$ induces aberrant lens cell behavior, other growth factors found in the ocular media, such as bone morphogenetic protein-7 (BMP-7) regulate normal cellular processes in the lens. There is a growing body of literature supporting the role of BMP-7 in antagonizing TGF $\beta$-driven EMT $^{[73]}$. BMP-7 functions as an endogenous inhibitor of TGF- $\beta$-induced EMT. Among other effects, it reverses the TGF- $\beta$-induced loss of the key epithelial protein, E-cadherin. Systemic administration of recombinant BMP-7 to mice with severe fibrosis resulted in reversal of EMT and repair of damaged epithelial structures, with repopulation of healthy epithelial cells, all presumably mediated via a $\mathrm{MET}^{[64]}$.
Inhibition of TGF $\beta$ signaling is a promising strategy to treat the disease. Accordingly, systemic injection of the endogenous TGF $\beta$ antagonist BMP7 can revert renal fibrosis in mice ${ }^{[16]}$. Paricalcitol, a synthetic vitamin D analog that suppresses the expression of TGF $\beta$ and of its type I receptor, also attenuates ureteral obstruction-induced renal fibrosis ${ }^{[117]}$. Inhibition of Snail may perhaps be a more specific alternative to treat kidney disease that would preserve the beneficial effects of TGF- $\beta$ secretion $^{[32]}$. Basic pathways of EMT, such as TGF- $\beta$ and Wnt, could provide potential therapeutic approach to inhibit endometriotic cell motility and invasiveness ${ }^{[76]}$. Manipulation of calciumsignaling pathways controlling EMT induction in cancer cells may therefore be an important therapeutic strategy for preventing metastase ${ }^{[93]}$. MicroRNAs (miRNAs) are non coding small RNA molecules that post-transcriptionally regulate protein expression via binding to the target genes leading to the regulation of EMT either as an inhibitor or as a promoter ${ }^{[118]}$.

\section{REFERENCES:}

1. Lamouille S., Xu J and Derynck R. Molecular mechanisms of epithelial-mesenchymal transition. Nat Rev Mol Cell Biol 2014; 15: 178-196.

2. Hay ED. An overview of epithelio-mesenchymal transformation. Acta Anat 1995; 154: 8-20.

3. Nieto MA, Huang RY, Jackson RA, Thiery JP EMT: 2016.Cell 2016; 166:21-45.

4. Boyer B, Tucker GC, Valles AM, Gavrilovic J, Thiery JP. Reversible transition towards a fibroblastic phenotype in a rat carcinoma cell line. Int J Cancer 1989; 4:69-75.

5. Revenu C, Streichan S. Dona E, Lecaudey V, Hufnagel L and Gilmour D. Quantitative cell polarity imaging defines leader-to-follower transitions during collective migration and the key role of microtubule-dependent adherens junction formation. Development 2014;141: 1282-1291.

6. Ridley A.J.; Schwartz M.A.; Burridge K; Firtel R.A.; Ginsberg M.H.; Borisy G; Parsons J.T; Horwitz, A.R. "Cell Migration: Integrating Signals from Front to back". Science 2003; 302 : 1704-1709.

7. Kyra C and Jordi C. A common framework for EMT and collective cell migration. Development 2016; 143:4291-4300.

8. O'Connor and Gomez EW. "Biomechanics of TGF $\beta$-induced epithelial-mesenchymal transition: implications for fibrosis and cancer." Clinical and translational medicine 2014. 
9. Tan B, Pascual A, de Beus A, Cooper K, Hull E. TGFbeta (transforming growth factor beta) and keratocyte motility in $24 \mathrm{~h}$ zebrafish explant cultures. Cell biology international. 2011;35: 1131-1139.

10. Arnoux V, Nassour M, L'Helgoualc'h A, Hipskind R, Savagner P. Erk5 controls slug expression and keratinocyte activation during wound healing. Mol Biol Cell 2008;19: 4738-4749.

11. Scita G, Di Fiore PP . The endocytic matrix. Nature 2010; 463:464-7310.

12. Nalluri, Sandeep M et al. "Cytoskeletal signaling in TGF $\beta$-induced epithelial-mesenchymal transition." Cytoskeleton 2015;72 11: 557-69.

13. Golinko MS, Joffe R, de Vinck D, Chandrasekaran E, Stojadinovic O, Barrientos S, Vukelic S, TomicCanic M, Brem H. Surgical pathology to describe the clinical margin of debridement of chronic wounds using a wound electronic medical record. Journal of the American College of Surgeons 2009; 209:254-260.

14. Nunan R, Campbell J, Mori R, Pitulescu ME, Jiang WG, Harding KG, Adams RH, Nobes CD, Martin P. Ephrin-Bs drive junctional downregulation and actin stress fiber disassembly to enable wound reepithelialization. Cell Rep 2015; 13:1380-1395.

15. Thomason HA, Cooper NH, Ansell DM, Chiu M, Merrit AJ, Hardman MJ, Garrod DR . Direct evidence that PKCalpha positively regulates wound re-epithelialization: correlation with changes in desmosomal adhesiveness. J Pathol 2012; 227:346-356.

16. Horejs CM. Basement membrane fragments in the context of the epithelial-to-mesenchymal transition. Eur J Cell Biol 2016; 95:427-440.

17. Wu SY, Ferkowicz M, McClay DR. "Ingression of primary mesenchyme cells of the sea urchin embryo: a precisely timed epithelial mesenchymal transition". Birth Defects Res C Embryo Today 2007; 81: 241-52.

18. Anne RJ, Martin AS, Burridge K, Richard FA., Mark GH., Gary B, Thomas PJ, Rick HA. "Cell Migration: Integrating Signals from Front to back". Science 2003; 302 : 1704-1709.

19. Takenawa T, Suetsugu S. The WASP-WAVE protein network: connecting the membrane to the cytoskeleton. Nature reviews Molecular cell biology 2007; 8:37-48.
20. Bartis D, Mise N, Mahida RY. Epithelialmesenchymal transition in lung development and disease: does it exist and is it important? Thorax 2014;69: 760-765.

21. Whiteman EL, Liu CJ, Fearon ER, Margolis B. The transcription factor snail represses Crumbs3 expression and disrupts apico-basal polarity complexes. Oncogene 2008; 27: 3875-3879.

22. Huang RY, Guilford P, Thiery JP . Early events in cell adhesion and polarity during epithelialmesenchymal transition. Journal of cell science 2012; 125: 4417-4422.

23. Mendez MG, Kojima S, Goldman RD. Vimentin induces changes in cell shape, motility, and adhesion during the epithelial to mesenchymal transition. FASEB journal : official publication of the Federation of American Societies for Experimental Biology 2010; 24:1838-1851.

24. Yang $\mathrm{X}$, Pursell $\mathrm{B}$, Lu S, Chang TK, Mercurio AM . Regulation of beta 4-integrin expression by epigenetic modifications in the mammary gland and during the epithelial-tomesenchymal transition. Journal of cell science 2009; 122: 2473-2480.

25. Arnoux V, Come C, Kusewitt D, Hudson L, Savagner P. Cutaneous wound reepithelialization: a partial and reversible EMT. In: Savagner P, editor. Rise and fall of epithelial phenotype: concepts of epithelial-mesenchymal transition. Berlin: Springer; 2005. 111-134.

26. Yan C, Grimm WA, Garner WL, Qin L, Travis T, Tan N, Han YP. Epithelial to mesenchymal transition in human skin wound healing is induced by tumor necrosis factor-alpha through bone morphogenic protein-2. The American journal of pathology 2010; 176: 2247-2258.

27. Aragona M, Dekoninck S, Rulands S, Lenglez S, Mascré C, Simons BD. Blanpain C. Defining stem cell dynamics and migration during wound healing in mouse skin epidermis. Nature Communications 2017; 8, Article number: 14684.

28. Shaw and Martin. Wound repair at a glance. Journal of Cell Science 2009; 122: 3209-3213.

29. Jordan NV, Johnson GL, Abell AN. Tracking the intermediate stages of epithelialmesenchymal transition in epithelial stem cells and cancer. Cell cycle (Georgetown, Tex) 2011; 10:2865-2873. 
30. Christiansen JJ, Rajasekaran AK. Reassessing epithelial to mesenchymal transition as a prerequisite for carcinoma invasion and metastasis. Cancer Res 2006. ; 66:8319-8326.

31. Zhao YL,ZhuRT, Sun YL.Epithelial-mesenchymal transition in liver fibrosis. Biomedical Reports. 2016;4: 269-274.

32. Welch-Reardon KM., Wu N, Hughes CW. A Role for Partial Endothelial-Mesenchymal Transitions in Angiogenesis? Thromb Vasc Biol. 2015; 35:303-308.

33. Savagner PP. The epithelial-mesenchymal transition (EMT) phenomenon. Annals of Oncology 2010; 21: 89-92.

34. Haensel D and Dai X. Epithelial-to-Mesenchymal Transition in Cutaneous Wound Healing: Where We Are and Where. Developmental dynamics $2018 ; 247: 473-480$.

35. Stone, R. C., Pastar, I., Ojeh, N., Chen, V., Liu, S., Garzon, K. I., \& Tomic-Canic, M. EpithelialMesenchymal Transition in Tissue Repair and Fibrosis. Cell and Tissue Research 2016; 365: 495-506.

36. Volk SW, Iqbal SA, Bayat A. Interactions of the Extracellular Matrix and Progenitor Cells in Cutaneous Wound Healing. Advances in wound care $2013 ; 2: 261-272$.

37. Thiery JP . Epithelial-mesenchymal transitions in tumour progression. Nat. Rev. Cancer 2002; $2: 442-454$.

38. Kalluri R, Weinberg RA. The basics of epithelialmesenchymal transition. The Journal of Clinical Investigation 2009; 119: 1420-1428.

39. Eming SA, Martin P, Tomic-Canic M . Wound repair and regeneration: mechanisms, signaling, and translation. Science translational medicine 2014; 6:265-266.

40. Cynthia E. Weber, MD, Neill Y. Li, Philip Y. Wai, MD, Paul C. Kuo, MD. Epithelial-Mesenchymal Transition, TGF- $\beta$ and Osteopontin in Wound Healing and Tissue Remodeling After Injury $\mathrm{J}$ Burn Care Res 2012;33:311-318.
41. Hashem HE, Mobasher MOI, Mohamed MZ and Alkhodary AAM. Efficiency of Adipose-Derived versus Bone Marrow-Derived Stem Cells in Modulation of Histopathological Changes and CD31 Immunoexpression during Wound Healing in Rats. Journal of Biochemistry \& Cell Biology 2018;1-9.

42. Coulombe PA. Wound epithelialization: accelerating the pace of discovery. The Journal of investigative dermatology 2003; 121: 219-230.

43. Baum CL, Arpey CJ. Normal cutaneous wound healing: clinical correlation with cellular and molecular events. Dermatologic surgery: official publication for American Society for Dermatologic Surgery $2005 ; 31: 674-686$.

44. McDonald TM, Pascual AS, Uppalapati CK Cooper KE, Leyva KJ, Hull EE. Zebrafish keratocyte explant cultures as a wound healing model system: differential gene expression \& morphological changes support epithelialmesenchymal transition. Experimental cell research 2013; 319:1815-1827.

45. Wynn TA and Ramalingam TR. Mechanisms of fibrosis: therapeutic translation for fibrotic disease. Nature medicine 2012;18: 1028-1040.

46. Prior BM, Yang HT, Terjung RL. "What makes vessels grow with exercise training?". Journal of Applied Physiology 2004; 97 : 1119-28.

47. Sagi $Z$ and Hieronymus T. The impact of the epithelial- Mesenchymal Transition Regulator Hepatocyte Growth Factor Receptor/ Met on Skin immunity by Modulating Langerhans Cell Migration. Front. Immunol 2018; 9:517.

48. Lepilina A, Coon AN, Kikuchi K, Holdway JE, Roberts RW, Burns CG, Poss KD. A dynamic epicardial injury response supports progenitor cell activity during zebrafish heart regeneration. Cell 2006; 127:607-619.

49. Boudoulas KD and Hatzopoulos AK. Cardiac repair and regeneration: the Rubik's cube of cell therapy for heart disease. Disease Models \& Mechanisms 2009; 2: 344-358.

50. Wynn, TA. Cellular and molecular mechanisms of fibrosis. J Pathol 2008; 214:199-210. 
51. Smart N,Risebro CA, Melville AA, Moses K, Schwartz RJ, Chien KR and Riley PR. Thymosin beta4 induces adult epicardial progenitor mobilization and neovascularization. Nature 2007; 445: 177-182.

52. Krainock M, Toubat O, Danopoulos S, Beckham A, Warburton D, Kim R. Epicardial Epithelial-toMesenchymal Transition in Heart Development and Disease. Journal of clinical medicine $2016 ; 5$.

53. Gilles C, Polette M, Zahm JM, Tournier JM, Volders L, Foidart JM, Birembaut P . Vimentin contributes to human mammary epithelial cell migration. Journal of cell science 1999; 112: 4615-4625.

54. Sikandar SS, Kuo AH, Kalisky T, Cai S, Zabala M, Hsieh RW. Lobo NA, Clarke MF. Role of epithelial to mesenchymal transition associated genes in mammary gland regeneration and breast tumorigenesis. Nature Communications 2017; 8, Article number: 1669.

55. You S, Avidan O, Tariq A, Ahluwalia I, Stark PC, Kublin CL, Zoukhri D. Role of epithelialmesenchymal transition in repair of the lacrimal gland after experimentally induced injury. Invest Ophthalmol Vis Sci. 2012;53:126-135.

56. Thiery JP, Acloque H, Huang R.J, Nieto MA . Epithelial-Mesenchymal Transitions in Development and Disease. Cell 2009; 139: 871-890.

57. Mani, SA, Guo, W, Liao, MJ, Eaton, EN, Ayyanan, A, Zhou, AY, Brooks, M, Reinhard, F, Zhang, CC, Shipitsin, M. The epithelial-mesenchymal transition generates cells with properties of stem cells. Cell 2008; 133: 704-715.

58. Li B, Zheng Y-W, Sano Y, Taniguchi H. Evidence for Mesenchymal-Epithelial Transition Associated with Mouse Hepatic Stem Cell Differentiation. PLoS ONE. 2011;6 :e17092.

59. Eastham A.M., Spencer H , Soncin F., Ritson S, Merry CL, Stern PL, Ward CM . Epithelialmesenchymal transition events during human embryonic stem cell differentiation. Cancer Res 2007; 67: 11254-11262.

60. Gabbiani G. The myofibroblast in wound healing and fibrocontractive diseases. The Journal of pathology 2003; 200: 500-503.
61. Castagnoli C, Trombotto C, Ondei S, Stella M, Calcagni M, Magliacani G, Alasia ST. Characterization of T-cell subsets infiltrating post-burn hypertrophic scar tissues. Burns 1997 ; 23:565-572.

62. Gazi H, Pope JE, Clements P, Medsger TA, Martin RW, Merkel PA, Kahaleh B, Wollheim FA, Baron M, Csuka ME, Emery P, Belch JF, Hayat S, Lally EV, Korn JH, Czirjak L, Herrick A, Voskuyl AE, Bruehlmann P, Inanc M, Furst DE, Black C, Ellman $\mathrm{MH}$, Moreland LW, Rothfield NF, Hsu V, Mayes M, McKown KM, Krieg T, Siebold JR. Outcome measurements in scleroderma: results from a delphi exercise. The Journal of rheumatology 2007 ; 34:501-509.

63. Potenta S., Zeisberg E., Kalluri R. The role of endothelial-to-mesenchymal transition in cancer progression. Br. J. Cancer 2008; 99:1375-1379.

64. Zeisberg M., et al. Bone morphogenic protein-7 inhibits progression of chronic renal fibrosis associated with two genetic mouse models. Am. J. Physiol. Renal Physiol. 2003; 285: F1060-F1067.

65. LeBleu VS and Raghu Kalluri. Blockade of PDGF receptor signaling reduces myofibroblast number and attenuates renal fibrosis. Kidney International 2011; 80,:1119 - 1121 .

66. Kendall RT and Feghali-Bostwick CA. Fibroblasts in fibrosis: novel roles and mediators. Front. Pharmacol 2014; 5: 123.

67. Zeisberg M., Shah A.A., Kalluri R. Bone morphogenic protein-7 induces mesenchymal to epithelial transition in adult renal fibroblasts and facilitates regeneration of injured kidney. J. Biol. Chem. 2005; 280:8094-8100.

68. Iwano M, Plieth D, Danoff TM., Xue C, Okada H, Neilson EG. Evidence that fibroblasts derive from epithelium during tissue fibrosis. J. Clin. Invest 2002; 110 :. 341-350.

69. Nitta, J.S. Kim, D. Mohuczy, K.E. Behrns. Murine cirrhosis induces hepatocyte epithelial mesenchymal transition and alterations in survival signaling pathways. Hepatology 2008; 48 : 909-919.

70. Yanez-Mo M., Lara-Pezzi, E, Dominguez-Jimenez MR., J.A. Jimenez H, Aguilera A, Sanchez TA, .Bajo MA, Alvarez V. Peritoneal dialysis and epithelial-to mesenchymal transition of mesothelial cells. N. Engl. J. Med 2003; 348 : 403-413. 
71. Hahn S, Nam M, Noh HJ, Lee DH, Han HW, Kim DH, Hahm KB, Hong SP, Yoo JH, Yoo J. Organoid-based epithelial to mesenchymal transition (OEMT) model: from an intestinal fibrosis perspective. Scientific Reports 2017; Article number: 2435.

72. Saika S., Ikeda K., Yamanaka O., Sato M., Muragaki Y., Ohnishi Y., Ooshima A., Nakajima Y., Namikawa K., Kiyama H. Transient adenoviral gene transfer of Smad7 prevents injury-induced epithelial-mesenchymal transition of lens epithelium in mice. Lab. Invest 2004; 84 : 12591270 .

73. Shu DY, Wojciechowski MC, Lovicu FJ. Bone Morphogenetic Protein-7 Suppresses TGF 32 Induced Epithelial-Mesenchymal Transition in the Lens: Implications for Cataract Prevention. Invest Ophthalmol Vis Sci 2017; 58:781-796.

74. Bulun SE. Endometriosis. New England Journal of Medicine 2009; 360:268-279.

75. Vargha R, Bender TO, Riesenhuber A, Endemann M, Kratochwill K, Aufricht C. Effects of epithelialto-mesenchymal transition on acute stress response in human peritoneal mesothelial cells. Nephrology, Dialysis, Transplantation 2008; 23: 3494-3500.

76. Yang Y-M, Yang W-X. Epithelial-to-mesenchymal transition in the development of endometriosis. Oncotarget 2017.;8: 41679-41689.

77. Kuwahara M, Hatoko M, Tada H, Tanaka A. E-cadherin expression in wound healing of mouse skin. J Cutan Pathol 2001; 28: 191-199.

78. Hsu CY, Lin CH, Jan YH, Su CY, Yao YC, Cheng HC. Huntingtin-Interacting Protein-1 Is an Early-Stage Prognostic Biomarker of Lung Adenocarcinoma and Suppresses Metastasis via Akt-mediated Epithelial-Mesenchymal Transition. Am J Respir Crit Care Med 2016; 193: 869-880.

79. Lee A, Chen M, Chen C, Yang C, Huang M , Liu Y. Reverse epithelial-mesenchymal transition contributes to the regain of drug sensitivity in tyrosine kinase inhibitor-resistant non-small cell lung cancer cells. PLOS ONE 2017; Published: July 6 .

80. Beaudry VG, Ihrie RA, Jacobs SB, Nguyen B, Pathak N, Park E, Attardi LD. Loss of the desmosomal component perp impairs wound healing in vivo. Dermatol Res Pract 2010:759731.
81. Patterson AL, Zhang L, Arango NA, Teixeira J, Pru JK. Mesenchymal-to-Epithelial Transition Contributes to Endometrial Regeneration Following Natural and Artificial Decidualization. Stem Cells and Development 2013; 22: 964-974.

82. Cousins, F. L. et al. Evidence from a mouse model that epithelial cell migration and mesenchymalepithelial transition contribute to rapid restoration of uterine tissue integrity during menstruation. PLoS ONE 2014; 9, e86378.

83. Powers CJ, McLeskey SW, Wellstein A. Fibroblast growth factors, their receptors and signaling. Endocrine-related cancer 2000; 7: 165-197.

84. Sogabe Y, Abe M, Yokoyama Y, Ishikawa O. Basic fibroblast growth factor stimulates human keratinocyte motility by Rac activation. Wound repair and regeneration : official publication of the Wound Healing Society [and] the European Tissue Repair Society 2006;14:457-462.

85. Sasaki T. The effects of basic fibroblast growth factor and doxorubicin on cultured human skin fibroblasts: relevance to wound healing. The Journal of dermatology 1992;19: 664-666.

86. Smith BN, Bhowmick NA. Role of EMT in Metastasis and Therapy Resistance. Journal of clinical medicine $2016 ; 5$.

87. Omenetti A, Porrello A, Jung Y, Yang L, Popov Y, Choi SS, Witek RP, Alpini G, Venter J, Vandongen HM, Syn WK, Baroni GS, Benedetti A, Schuppan D, Diehl AM. Hedgehog signaling regulates epithelial-mesenchymal transition during biliary fibrosis in rodents and humans. The Journal of clinical investigation 2008; 118:3331-3342.

88. Toyoda M, Takayama H, Horiguchi N, Otsuka T, Fukusato T, Merlino G, Takagi H, Mori M . Overexpression of hepatocyte growth factor/ scatter factor promotes vascularization and granulation tissue formation in vivo. FEBS Lett. 2001; 509:95-100.

89. Wang Y, Weil BR, Herrmann JL, Abarbanell AM, Tan J, Markel TA, Kelly ML, Meldrum DR. MEK, p38, and PI-3K mediate cross talk between EGFR and TNFR in enhancing hepatocyte growth factor production from human mesenchymal stem cells. American journal of physiology Cell physiology 2009;297: C1284-C1293. 
90. Ramirez H, Patel SB, Pastar I. The Role of TGF beta Signaling in Wound Epithelialization. Advances in wound care 2014;3:482-491.

91. Bielefeld KA, Amini-Nik S, Alman BA. Cutaneous wound healing: recruiting developmental pathways for regeneration. Cell Mol Life Sci 2013;70:2059-2081.

92. Ito M, Yang Z, Andl T, Cui C, Kim N, Millar SE, Cotsarelis G. Wnt-dependent de novo hair follicle regeneration in adult mouse skin after wounding. Nature 2007; 447:316-320.

93. Davis FM, Azimi I, Faville RA, Peters AA, Jalink K, Putney JW Jr, Goodhill GJ, Thompson EW, Roberts-Thomson SJ, Monteith GR. Induction of epithelial-mesenchymal transition (EMT) in breast cancer cells is calcium signal dependent. Oncogene 2014; 33:2307-16.

94. Medici D, Hay ED, Olsen BR. Snail and Slug Promote Epithelial-Mesenchymal Transition through $\beta$-Catenin-T-Cell Factor-4-dependent Expression of Transforming Growth Factor- $\beta 3$. Bronner-Fraser M, ed. Molecular Biology of the Cell 2008;19:4875-4887.

95. McCluskey $\mathrm{J}$ and Martin P. Analysis of the tissue movements of embryonic wound healing--Dil studies in the limb bud stage mouse embryo. Dev Biol 1995;170: 102-114.

96. Redd MJ, Cooper L, Wood W, Stramer B, Martin $\mathrm{P}$. Wound healing and inflammation: embryos reveal the way to perfect repair. Philos Trans $\mathrm{R}$ Soc Lond B Biol Sci 2004; 359:777-784.

97. Grotegut S, von Schweinitz D, Christofori G, Lehembre F. Hepatocyte growth factor induces cell scattering through MAPK/Egr-1-mediated upregulation of Snail. The EMBO journal 2006; 25:3534-3545.

98. Hudson LG, Newkirk KM, Chandler HL, Choi C, Fossey SL, Parent AE, Kusewitt DF. Cutaneous wound reepithelialization is compromised in mice lacking functional Slug (Snai2) Journal of dermatological science 2009; 56:19-26.

99. Kusewitt DF, Choi C, Newkirk KM, Leroy P, Li Y, Chavez MG, Hudson LG. Slug/Snai2 is a downstream mediator of epidermal growth factor receptor-stimulated reepithelialization. The Journal of investigative dermatology 2009; 129:491-495.
100. Shirley SH, Hudson LG, He J, Kusewitt DF . The skinny on Slug. Mol Carcinog. 2010; 49:851-861.

101.Savagner P, Kusewitt DF, Carver EA, Magnino F, Choi C, Gridley T, Hudson LG. Developmental transcription factor slug is required for effective re-epithelialization by adult keratinocytes. Journal of cellular physiology 2005; 202:858-866.

102. Vincent T, Neve EP, Johnson JR, Kukalev A, Rojo F, Albanell J, Pietras K, Virtanen I, Philipson L, Leopold PL, Crystal RG, de Herreros AG, Moustakas A, Pettersson RF, Fuxe J.A. SNAIL1-SMAD3/4 transcriptional repressor complex promotes TGF-beta mediated epithelialmesenchymal transition. Nature cell biology 2009; 11:943-950.

103.Savagner P. Leaving the neighborhood: molecular mechanisms involved during epithelial-mesenchymal transition. Bioessays $2001 ; 23: 912-923$.

104.Gawronska-Kozak B, Grabowska A, KurPiotrowska A, Kopcewicz M. Foxn1 Transcription Factor Regulates Wound Healing of Skin through Promoting Epithelial-Mesenchymal Transition. PloS one 2016;11:e0150635.

105. Carretero M, Escamez MJ, Garcia M, Duarte B, Holguin A, Retamosa L, Jorcano JL, Rio MD, Larcher F. In vitro and in vivo wound healingpromoting activities of human cathelicidin LL-37. The Journal of investigative dermatology 2008; 128: 223-236.

106. Corallino S, Malabarba MG, Zobel M, Di Fiore PP. Epithelial-to-Mesenchymal Plasticity Harnesses Endocytic Circuitries and Giorgio Scita. Front Oncol 2015.; 5: 45.

107.Han YP, Tuan TL, Hughes M, Wu H, Garner WL. Transforming growth factor-beta-and tumor necrosis factor-alpha-mediated induction and proteolytic activation of MMP-9 in human skin. J Biol Chem 2001; 276: 22341-22350.

108. Galichon P, Hertig A. Epithelial to mesenchymal transition as a biomarker in renal fibrosis: are we ready for the bedside? Fibrogenesis Tissue Repair $2011 ; 6: 11$.

109. Koo V, El Mekabaty A, Hamilton P, Maxwell P, Sharaf O, Diamond J, Watson J, Williamson K. Novel in vitro assays for the characterization of EMT in tumourigenesis. Cell Oncol 2010; 32: 67-76. 
110.Stegmann TJ, Hoppert T, Schneider A, Gemeinhardt S, Köcher M, Ibing R, Strupp G. "[Induction of myocardial neoangiogenesis by human growth factors. A new therapeutic approach in coronary heart disease]". Herz (in German). 2000; 25: 589-99.

111.Bidarra SJ, Oliveira P, Rocha S, Saraiva DP, Oliveira C, Barrias CC. A 3D in vitro model to explore the inter-conversion between epithelial and mesenchymal states during EMT and its reversion. Sci Rep 2016;6: 27072.

112.Liao C, Li P, Lee Y, Li S, Chu S. Lipocalin 2 induces the epithelial-mesenchymal transition in stressed endometrial epithelial cells: possible correlation with endometriosis development in a mouse model, REPRODUCTION, 2014; 147: 179-187.

113.Yu, Y., \& Elble, R. C. Homeostatic Signaling by Cell-Cell Junctions and Its Dysregulation during Cancer Progression. Journal of Clinical Medicine 2016; 5: 26.

114.Grande MT, Sánchez-Laorden B, López-Blau C, De Frutos CA, Boutet A1, Arévalo M, Rowe RG, Weiss SJ, López-Novoa JM, Nieto MA. Snaill-induced partial epithelial-to-mesenchymal transition drives renal fibrosis in mice and can be targeted to reverse established disease. Nat Med. $2015 ; 989-997$.
115.Du B, Shim JS . Targeting Epithelial-Mesenchyma Transition (EMT) to Overcome Drug Resistance in Cancer. Molecules 2016.; 21. E 965.

116.Zeisberg M, Hanai J, Sugimoto H, Mammoto T, Charytan D, Strutz F, Kalluri R. BMP-7 counteracts TGF-betal-induced epithelial-to-mesenchymal transition and reverses chronic renal injury. Nat Med. 2008 ; 9:964-968.

117. Tan X, Li Y., Liu Y . Paricalcitol attenuates renal interstitial fibrosis in obstructive nephropathy. J. Am. Soc. Nephrol. 2006; 17 : 3382-3393.

118.Li PJ, Zou K, Yu L, Zhao W, Lu Y, Mao J, Wang B, Wang L, Song B, Li L. MicroRNA-140 Inhibits the Epithelial-Mesenchymal Transition and Metastasis in Colorectal Cancer. Molecular Therapy - Nucleic Acids 2018; 10: 426-437. 